\title{
Schistosomiasis in Malawi: a systematic review
}

\author{
Peter Makaula ${ }^{1 *}$, John R Sadalaki ${ }^{2}$, Adamson S Muula ${ }^{2}$, Sekeleghe Kayuni ${ }^{3}$, Samuel Jemu ${ }^{4}$ and Paul Bloch ${ }^{5}$
}

\begin{abstract}
Introduction: Schistosomiasis remains an important public health problem that undermines social and economic development in tropical regions of the world, mainly Sub-Saharan Africa. We are not aware of any systematic review of the literature of the epidemiology and transmission of schistosomiasis in Malawi since 1985. Therefore, we reviewed the current state of knowledge of schistosomiasis epidemiology and transmission in this country and identified knowledge gaps and relevant areas for future research and research governance.

Methods: We conducted computer-aided literature searches of Medline, SCOPUS and Google Scholar using the keywords: "schistosomiasis", "Bilharzia", "Bulinus" and "Biomphalaria" in combination with "Malawi". These searches were supplemented by iterative reviews of reference lists for relevant publications in peer reviewed international scientific journals or other media. The recovered documents were reviewed for their year of publication, location of field or laboratory work, authorship characteristics, ethics review, funding sources as well as their findings regarding parasite and intermediate host species, environmental aspects, geographical distribution, seasonality of transmission, and infection prevalence and intensities.
\end{abstract}

Review: A total of 89 documents satisfied the inclusion criteria and were reviewed. Of these, 76 were published in international scientific journals, 68 were peer reviewed and 54 were original research studies. Most of the documents addressed urinary schistosomiasis and about two thirds of them dealt with the definitive host. Few documents addressed the parasites and the intermediate hosts. While urinary schistosomiasis occurs in most parts of Malawi, intestinal schistosomiasis mainly occurs in the central and southern highlands, Likoma Island and Lower Shire. Studies in selected communities estimated prevalence rates of up to $94.9 \%$ for Schistosoma haematobium and up to 67.0\% for Schistosoma mansoni with considerable geographical variation. The main intermediate host species are Bulinus globosus and Bulinus nyassanus for urinary schistosomiasis and Biomphalaria pfeifferi for intestinal schistosomiasis. Seasonality of transmission tends to vary according to geographical, environmental, biological and behavioural factors.

Conclusion: Transmission of schistosomiasis in Malawi appears to be highly focal, with considerable variation in space and time. Many locations have not been covered by epidemiological investigations and, thus, information on the transmission of schistosomiasis in Malawi remains fragmented. Functional infection risk assessment systems based on systematic investigations and surveillance are required for developing informed prevention and control strategies.

Keywords: Bilharzia, Biomphalaria, Bulinus, Schistosomiasis, Schistosoma haematobium, Schistosoma mansoni, Malawi

\section{Introduction}

Schistosomiasis ranks second only to malaria among the parasitic diseases affecting humans with regard to the number of people infected and the risk of becoming infected globally. The World Health Organization (WHO) recognizes schistosomiasis as one of the 17 neglected tropical diseases (NTDs), which are mostly persistent and prevalent in people and communities living in poverty and

\footnotetext{
* Correspondence: petmakau@yahoo.co.uk

'Research for Health Environment and Development, P.O. Box 345, Mangochi, Malawi

Full list of author information is available at the end of the article
}

social exclusion, and jointly affects more than 1 billion people worldwide [1,2]. It is estimated that schistosomiasis infects more than 200 million people globally and causes an annual loss of between 1.7 and 4.5 million disability adjusted life years (DALYs) [3-7]. A recent meta-analysis challenges these estimates and argues that a $0.5 \%$ disability weight assigned to schistosomiasis by the WHO is too low [8]. The authors noted that $2-15 \%$ disability weight is more realistic based on assessments of the different functional impairments of a person with schistosomiasis. It is estimated that more than $97 \%$ of all cases occur in Africa [9], and the highest prevalence estimates and infection 
intensities are usually found in school-age children, adolescents and young adults $[10,11]$ as well as in infants and pre-school children [12]. Schistosomiasis negatively impacts on children's physical development and school performance, and the debilitation caused by untreated infections undermines social and economic development in heavily affected areas [13-16]. Schistosomiasis may also negatively affect the tourism industry of endemic countries as a result of fear among tourists and visitors of becoming infected [17]. The strategy recommended by WHO for the control of schistosomiasis includes preventive chemotherapy, which is an intervention that allows the regular and coordinated administration of quality-assured, safe, single dose medicines on a large scale [18].

In Malawi, urinary schistosomiasis caused by Schistosoma haematobium is highly prevalent in the lakeshore and southern region districts, while intestinal schistosomiasis caused by Schistosoma mansoni predominates on the central plains and in the northern region's districts [19]. The National Schistosomiasis Control Programme (NSCP) estimates that $40-50 \%$ of the total Malawian population is at risk of becoming infected with schistosomiasis [20]. However, these national estimates appear to be derived from old surveys suffering from selection bias for high-risk schools. A national survey of primary school pupils in 2003 found large variation in the prevalence estimates of S. haematobium and S. mansoni infections among school children across the nation [20]. For S. haematobium, the estimates ranged from $0-43.1 \%$ with an average rate of $6.9 \%$. For $S$. mansoni, the estimates ranged from $0-4.3 \%$, with an average rate of $0.4 \%$. The national survey used the urine filtration method to detect $S$. haematobium eggs in urine and the Kato-Katz smear method to detect S. mansoni eggs in stool. Single urine and stool samples were collected from every child and tested. These prevalence estimates were much lower than expected and it was therefore concluded that schistosomiasis transmission in Malawi is highly focal. This result implies that local estimates would be more reliable than national estimates in guiding the selection of control strategies to be implemented at district or sub-district level [5,21]. Unfortunately, only few districts in Malawi, if any, have local prevalence estimates to guide the planning and implementation of prevention and control measures.

To our knowledge, this review is the third of a series of systematic literature reviews pertaining to schistosomiasis in Malawi. The first review, which was published by Blair in 1956 [22], revealed that S. mansoni infection was mainly observed in the northern district of Karonga and the extreme south, whereas S. haematobium infection was predominant in the lowlands. The second review, which was carried out by Teesdale in 1985 [19], indicated that $S$. mansoni infection was far more widespread than previously thought, predominantly in the central plateau, and that $S$. haematobium infection was highly prevalent in the southern region. Both infections occurred with moderate to high intensities along the lakeshore plain. The present paper systematically reviews the existing literature on schistosomiasis in Malawi, dating back to 1985 , which was the last time a similar review was conducted in this country.

The main objective of this review is to update our understanding of the epidemiology and transmission of schistosomiasis in Malawi. The specific objectives are:

1. To characterize the existing literature on schistosomiasis in Malawi published or not published in scientific journals since 1985, with emphasis on year of publication, location of field or laboratory work, authorship, involved organizations, funding sources and ethics.

2. To summarize what is known about schistosomiasis in Malawi, in terms of parasite and intermediate host species, environmental aspects, geographical distribution, seasonality of occurrence and transmission, and infection prevalence and intensities.

3. To provide an update on existing schistosomiasis control efforts in Malawi with emphasis on policies, strategies and actions for integrated prevention and control of NTDs.

4. To identify knowledge gaps and research needs pertaining to the topic of schistosomiasis in Malawi.

\section{Methods}

We carried out a systematic literature review of all online articles on schistosomiasis in Malawi since 1985 and published in the English language. As a first step, we undertook a computer-aided search of the electronic online databases Medline, SCOPUS and Google Scholar using the keywords: "schistosomiasis", "Bilharzia", "Bulinus" and "Biomphalaria" in combination with "Malawi".

As a second step, we supplemented the searches by iterative reviews of reference lists of all included scientific publications for relevant additional literature available on the internet, including information websites. This additional literature included studies published in peer reviewed scientific journals, but also investigations available only in project reports, student dissertations and theses.

For the purpose of this review, a "research article" is defined as an original piece of scientific work published in an international and peer reviewed scientific journal; a "review article" is defined as a summarisation of existing knowledge and recent insights into specific research areas published in an international and peer reviewed scientific journal; a "project report" is defined as an 
original piece of scientific work, which has been published but not in an international and peer reviewed scientific journal; a "case report" is defined as a piece of scientific work, published in an international and peer reviewed journal, of one or more patients who have acquired schistosomiasis and received treatment; and a "letter to the editor" is a brief message written to an editor of an international and peer reviewed scientific journal, seeking to provide information or clarification on a certain topic of interest to the readers.

Inclusion and exclusion criteria for publications were defined prior to the review. Publications were included if reporting about findings from an area relating to schistosomiasis including laboratory work carried out in Malawi, or carried out outside of Malawi, but based on samples or specimens originating from Malawi since 1985, and if contributing factual knowledge about schistosomiasis epidemiology and transmission in Malawi. Publications were excluded if reporting on field or laboratory work on schistosomes based on samples or specimens originating from outside of Malawi, if field or laboratory work was carried out in Malawi before 1985, if only addressing theoretical issues, or if only expressing assumptions, beliefs, opinions, perceptions and attitudes about schistosomiasis.

As a third step, the documents were categorized into three groups according to the forms of schistosomiasis addressed (i.e. urinary schistosomiasis, intestinal schistosomiasis or a combination of the two). Each of these groups were further divided into four sub-groups according to the main focus of the study, namely: a) the definitive human host of the parasites, b) the intermediate host species of the parasites, c) the causative parasite species of the disease, e.g. studies that involved techniques for the detection of parasites in samples or specimens, or d) a mixture, i.e. any combination of two or all of the first focus areas of human, intermediate host and parasite. The decision tree for the inclusion or exclusion of documents and how they were assigned into these groups and subgroups is shown in Figure 1.

Each of the included documents were reviewed for their basic characteristics including area of focus, year of publication, authorship, organizations involved, funding sources, location of field or laboratory work, adherence to ethics as well as its findings related to intermediate host and parasite species, geographical distribution, seasonality of occurrence and transmission, infection prevalence estimates and intensities, and relevance to tourism and other associated conditions.

\section{Review}

\section{Literature on schistosomiasis in Malawi since 1985}

The literature search yielded 101 documents responding to the applied keywords and published between 1985 and mid 2014. After further reviewing the literature and applying the inclusion and exclusion criteria, 12 documents failed to be included because they were not reporting on work carried out in or relating to Malawi. Thus, 89 documents met the inclusion criteria for this review. These 89 documents included 76 (85\%) documents published in international scientific journals as research articles, review articles, case reports or letters to the editor; $68(76 \%)$ were peer reviewed papers and 54 (61\%) comprised original research articles. Characteristics of the reviewed documents are summarized in Table 1.

Of the 89 reviewed documents, $53(60 \%)$ of them focused on urinary schistosomiasis, whereas 33 (37\%) addressed both urinary and intestinal schistosomiasis. Only 3 (3\%) documents focused exclusively on intestinal schistosomiasis.

The disparities in areas of focus were also observed in the sub-groups where, of the 53 documents in the urinary schistosomiasis group, 35 (66\%) focused on humans, 12 (23\%) focused on intermediate hosts and the remaining 6 (11\%) focused on human, intermediate host and/or parasite. Of the 33 documents that focused on both types of schistosomiasis, 23 (70\%) dealt with humans, 3 (9\%) covered intermediate host(s), and 7 (21\%) focused on human, intermediate host and/or parasite. Of the 3 documents in the intestinal schistosomiasis group, 1 (33\%) focused on humans and $2(67 \%)$ covered the parasite. Figure 1 summarizes the decision tree and how the documents have been classified according to their areas of focus.

\section{Year of publication, authorship, involved organizations, funding sources and ethics}

All 89 documents included in this review were published over a period of 29 years between 1985 and mid 2014, which corresponds to an average publication rate of 3.0 papers per year. Further review revealed that publications on schistosomiasis in relation to Malawi have been increasing over time since 1985 (Figure 2). Scientific research and review articles dominated and represented 58 (65\%) of the 89 documents. Moreover, 18 (20\%) documents were case reports on foreign patients who were treated for schistosomiasis after visiting Malawi, 9 (10\%) were letters to the editors of peer reviewed journals and 4 (5\%) were project reports. We categorized 62 of the 89 documents as research articles, review articles or project reports. Of these documents, 26 (42\%) were produced exclusively by research institutions based outside of Malawi; 5 (8\%) were produced exclusively by local research institutions and $31(50 \%)$ were produced by a combination of foreign and local research institutions (Table 2).

In total, 411 authors appeared on all 89 documents, giving a mean rate of 4.6 authors per document and a median of 4 authors (range 1-14) per document. Several authors appeared on more than one document. In total, there were 272 different authors involved in the publication of the 89 


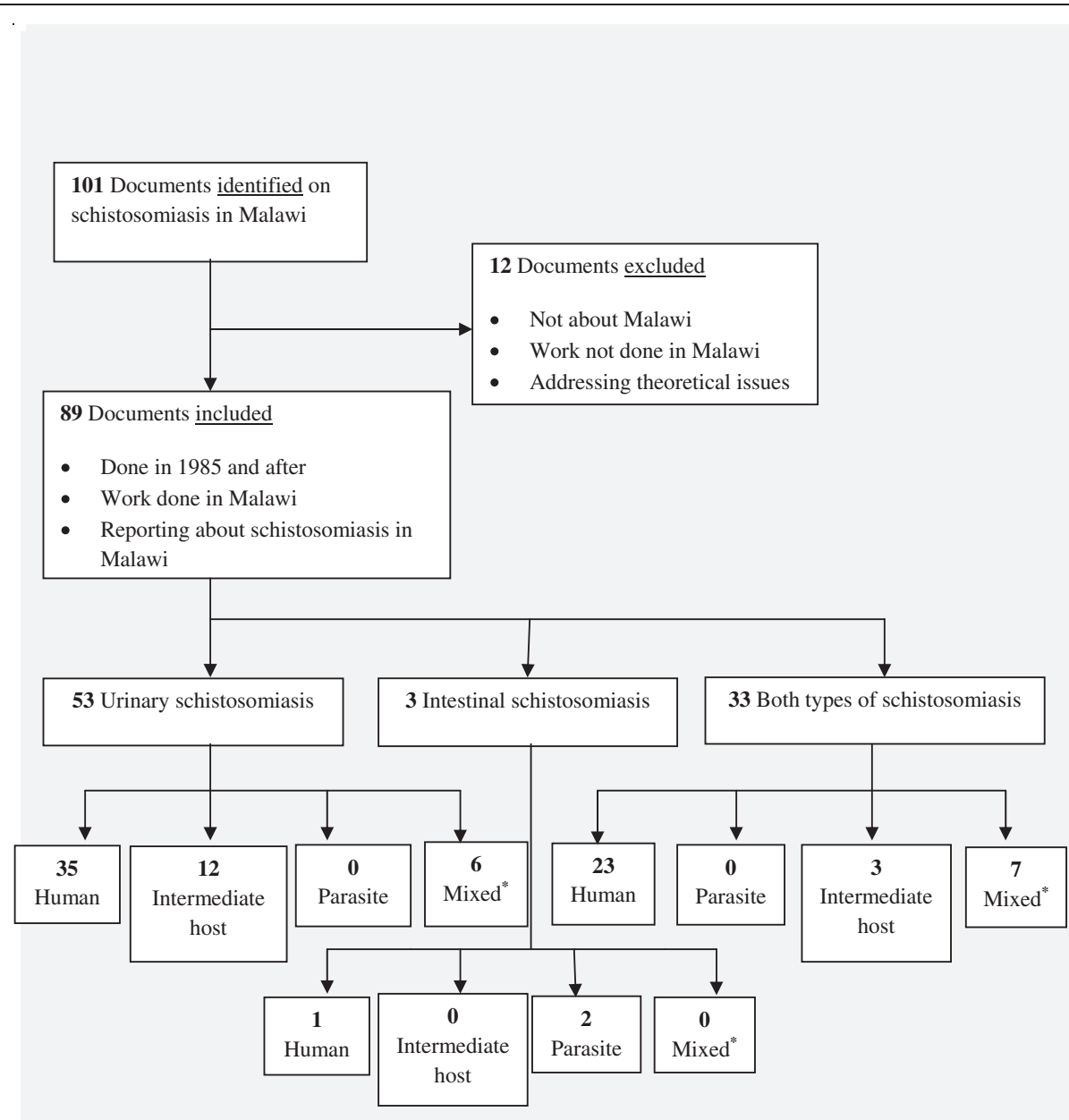

Figure 1 Decision tree showing the number of included and excluded documents identified from online literature searches. ${ }^{*}$ Mixed $=$ any document focusing on combination of (i) human, intermediate host and parasite; (ii) human and intermediate host; (iii) human and parasite or (iv) intermediate host and parasite.

documents and 37 (14\%) of these were Malawian nationals. Further analysis of authorship of the 89 reviewed documents showed that $10(11 \%)$ had a Malawian as a first author and the remaining $79(89 \%)$ had a nonMalawian as a first author. All 10 documents with a Malawian as a first author and 53 (67\%) of the 79 documents with a non-Malawian as a first author originated from work carried out in Malawi. The remaining 26 (33\%) documents with a non-Malawian as a first author originated from work carried out outside Malawi, such as laboratory studies based on samples and specimens originating from Malawi. Of the 62 documents categorized as research articles, review articles and project reports, 61 (98\%) were funded by non-Malawi-based

Table 1 Characteristics of the included and reviewed documents

\begin{tabular}{lllll}
\hline Document type & Eligible documents & Published in scientific journal & Peer reviewed papers & Original research studies \\
\hline Research article & 54 & 47 & 47 & 54 \\
Case report & 18 & 18 & 18 & 0 \\
Letter to the editor & 9 & 7 & 0 & 0 \\
Project report & 4 & 1 & 0 & 0 \\
Review article & 4 & 3 & 3 & 0 \\
Total & $\mathbf{8 9}$ & $\mathbf{7 6}$ & $\mathbf{6 8}$ & $\mathbf{5 4}$ \\
\hline
\end{tabular}




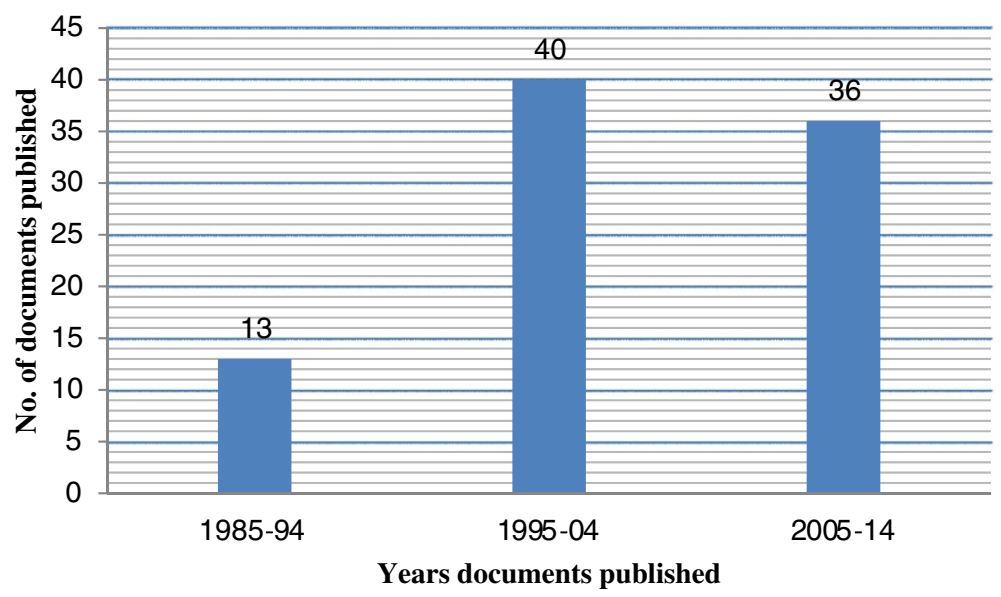

Figure 2 Number of reviewed schistosomiasis related documents published between 1985 and mid 2014 .

agencies, while only one student's study was funded in Malawi, representing 2\% of the documents.

Even though most of the reviewed publications derive from single-standing studies, four major groups of scientists have contributed comprehensively to publishing the findings from their research. These groups comprised several researchers who collaborated on specific research programs on schistosomiasis and related aspects in Malawi, namely 1) a group from Malawi, particularly from institutions within the University of Malawi, involved in publishing 17 (36\%) scientific papers $[6,19,20,23,26,29,31,55,75,80,83,84,96,99,101,102]$ as first authors; 2) a group from USA involved in publishing 13 (28\%) scientific papers $[32,45,61,67-73,100,106,107]$ as first authors; 3) a group from Denmark involved in publishing $10(21 \%)$ scientific papers $[6,57-59,63,66,74,85,105]$ as first authors and 4) a group from Norway involved in publishing $7(15 \%)$ scientific papers $[24,27,41-44,109]$ as first authors. It was not uncommon for a number of authors or institutions to collaborate, especially the groups from Denmark and the USA, and the groups from University of Malawi and Norway. In total, these four groups produced 47 (53\%) of all documents reviewed. Of all the authors of the reviewed documents, Madsen from Denmark and Stauffer from USA were the most productive researchers, in terms of authorship and co-authorship of schistosomiasis related papers from Malawi. Of the 54 original research articles, these two authors appear individually or together on 19 (35\%) of the articles.

All studies involving human subjects were reviewed for their ethical clearance with relevant authorities in Malawi or elsewhere prior to implementation. In total, 34 (63\%) of the 54 original research studies involved human subjects. Of these, 14 (41\%) mentioned that ethical clearance had been sought from the College of Medicine Research Ethics Committee (COMREC), 12 (35\%) had sought ethical clearance from the Ministry of Health's
National Health Sciences Research Committee (NHSRC), 1 (3\%) from the District Health Office and 1 (3\%) from the Institutional Ethics Review Board of the University of North Carolina. The remaining 6 (18\%) documents did not report on ethical clearance. The detailed characteristics of the reviewed documents are summarised in Table 2.

\section{Parasite and intermediate host species for human schistosomiasis in Malawi}

There are two known species of parasites causing schistosomiasis in humans in Malawi, namely Schistosoma haematobium for the urinary form, and Schistosoma mansoni for the intestinal form. The review revealed that both species are present in Malawi. Moreover, two snail species are known to act as intermediate hosts for urinary schistosomiasis in Malawi, namely the well recognised host Bulinus globosus and the recently implicated Bulinus nyassanus [74], while Biomphalaria pfeifferi acts as intermediate host for intestinal schistosomiasis [108].

\section{Seasonality of transmission of schistosomiasis in Malawi}

There are two possibilities for transmission of schistosomiasis within the Lake Malawi area, namely 1) by cercariae produced within the lake or 2) by cercariae transported into the lake by inflowing streams or rivers, or overflowing ponds close to the shores of the lake. $S$. haematobium appears to be the only schistosome transmitted in this lake. Transmission of schistosomiasis in the lake depends on factors such as human activity, wind and wave action, temperature, rainfall, lake level and density of intermediate hosts. Some studies have documented that transmission of urinary schistosomiasis in the southern part of Lake Malawi occurs mainly along sandy beaches where B. nyassanus is widely distributed or along relatively protected shore-lines such as harbours or calm bays where B. globosus is the primary intermediate host. Here, transmission has been documented to be low 
Table 2 Characteristics of schistosomiasis related documents included in the review; The documents have been stratified by area of focus

\begin{tabular}{|c|c|c|c|c|c|c|c|c|}
\hline Serial No. & Ref. No. & $\begin{array}{l}\text { Study area of focus/First author } \\
\text { name and year }\end{array}$ & $\begin{array}{l}\text { Total number } \\
\text { of authors }\end{array}$ & $\begin{array}{l}\text { Type of } \\
\text { document }\end{array}$ & $\begin{array}{l}\text { Originating } \\
\text { country }\end{array}$ & $\begin{array}{l}\text { Place(s) where } \\
\text { study was done }\end{array}$ & Funding/Ethics ${ }^{\pi}$ & $\begin{array}{l}\text { Implementing } \\
\text { agency }^{a}\end{array}$ \\
\hline & & A. Urinary-human & & & & & & \\
\hline 1 & [23] & Pullanikkatil, 2014 & 5 & Research & Malawi & Zomba & Foreign/DHO & Local \\
\hline 2 & [24] & Jourdan, 2013a & 7 & Research & Norway & Blantyre & Foreign/COM & Combined \\
\hline 3 & [25] & Jourdan, 2013b & 1 & Research & Norway & Blantyre & Foreign/COM & Foreign \\
\hline 4 & [26] & Logan, 2013 & 10 & Case report & England & - & - & $\mathrm{n} / \mathrm{a}$ \\
\hline 5 & [27] & Chipeta, 2013 & 3 & Research & Malawi & Chikhwawa & Foreign/COM & Local \\
\hline 6 & [28] & Kjetland, 2012 & 3 & Review & Norway & - & Foreign & Foreign \\
\hline 7 & [29] & Blach, 2012 & 5 & Research & Scotland & - & Foreign & Foreign \\
\hline 8 & {$[30]$} & Kayuni, 2012 & 1 & Research & Malawi & Mangochi & Foreign/MOH & Local \\
\hline 9 & [31] & Yildirmak, 2012 & 4 & Case report & Turkey & - & - & $\mathrm{n} / \mathrm{a}$ \\
\hline 10 & {$[32]$} & Kapito-Tembo, 2009 & 7 & Research & Malawi & Blantyre & Foreign/UNC & Combined \\
\hline 11 & [33] & Save the Children, 2008 & 1 & Project report & USA & Mangochi & Foreign/MOH & Foreign \\
\hline 12 & [34] & Yokota, 2007 & 13 & Case report & Japan & - & - & $\mathrm{n} / \mathrm{a}$ \\
\hline 13 & [35] & Van Delft, 2007 & 4 & Case report & Netherlands & - & - & $\mathrm{n} / \mathrm{a}$ \\
\hline 14 & {$[36]$} & Tsuboi, 2006 & 10 & Case report & Japan & - & - & $\mathrm{n} / \mathrm{a}$ \\
\hline 15 & {$[37]$} & Moore, 2005 & 2 & Letter & England & - & - & $\mathrm{n} / \mathrm{a}$ \\
\hline 16 & [38] & Tambo, 2004 & 7 & Case report & Japan & - & - & $\mathrm{n} / \mathrm{a}$ \\
\hline 17 & [39] & Kitayama, 2004 & 14 & Case report & Japan & - & - & $\mathrm{n} / \mathrm{a}$ \\
\hline 18 & {$[40]$} & Nicolas, 1998 & 5 & Letter & France & - & - & $\mathrm{n} / \mathrm{a}$ \\
\hline 19 & [41] & Silwal, 1997 & 4 & Case report & England & - & - & $\mathrm{n} / \mathrm{a}$ \\
\hline 20 & {$[42]$} & Kjetland, 1996 & 10 & Research & Norway & Mangochi & Foreign/COM & Combined \\
\hline 21 & [43] & Helling-Giese, 1996 & 12 & Research & Germany & Mangochi & Foreign/COM & Combined \\
\hline 22 & [44] & Poggensee, 1996 & 14 & Research & Germany & Mangochi & Foreign/COM & Combined \\
\hline 23 & {$[45]$} & Gundersen, 1996 & 9 & Research & Norway & Mangochi & Foreign/COM & Combined \\
\hline 24 & {$[46]$} & Cetron, 1996a & 9 & Research & USA & Lilongwe & Foreign/MOH & Combined \\
\hline 25 & [47] & Potasman, 1996 & 4 & Case report & Israel & - & - & $\mathrm{n} / \mathrm{a}$ \\
\hline 26 & {$[48]$} & TDR News, 1996 & 1 & Letter & Switzerland & Mangochi & - & $\mathrm{n} / \mathrm{a}$ \\
\hline 27 & [49] & Hunt, 1995 & 1 & Letter & England & Mangochi & - & $\mathrm{n} / \mathrm{a}$ \\
\hline 28 & {$[50]$} & Potasman, 1995 & 2 & Case report & Israel & - & - & n/a \\
\hline 29 & [51] & Herwaldt,1995 & 5 & Case report & USA & - & - & $\mathrm{n} / \mathrm{a}$ \\
\hline 30 & [52] & Loefler, 1994 & 1 & Letter & Kenya & Salima & - & $\mathrm{n} / \mathrm{a}$ \\
\hline 31 & [53] & Eulderink, 1994 & 4 & Case report & Netherlands & - & - & $\mathrm{n} / \mathrm{a}$ \\
\hline
\end{tabular}


Table 2 Characteristics of schistosomiasis related documents included in the review; The documents have been stratified by area of focus (Continued)

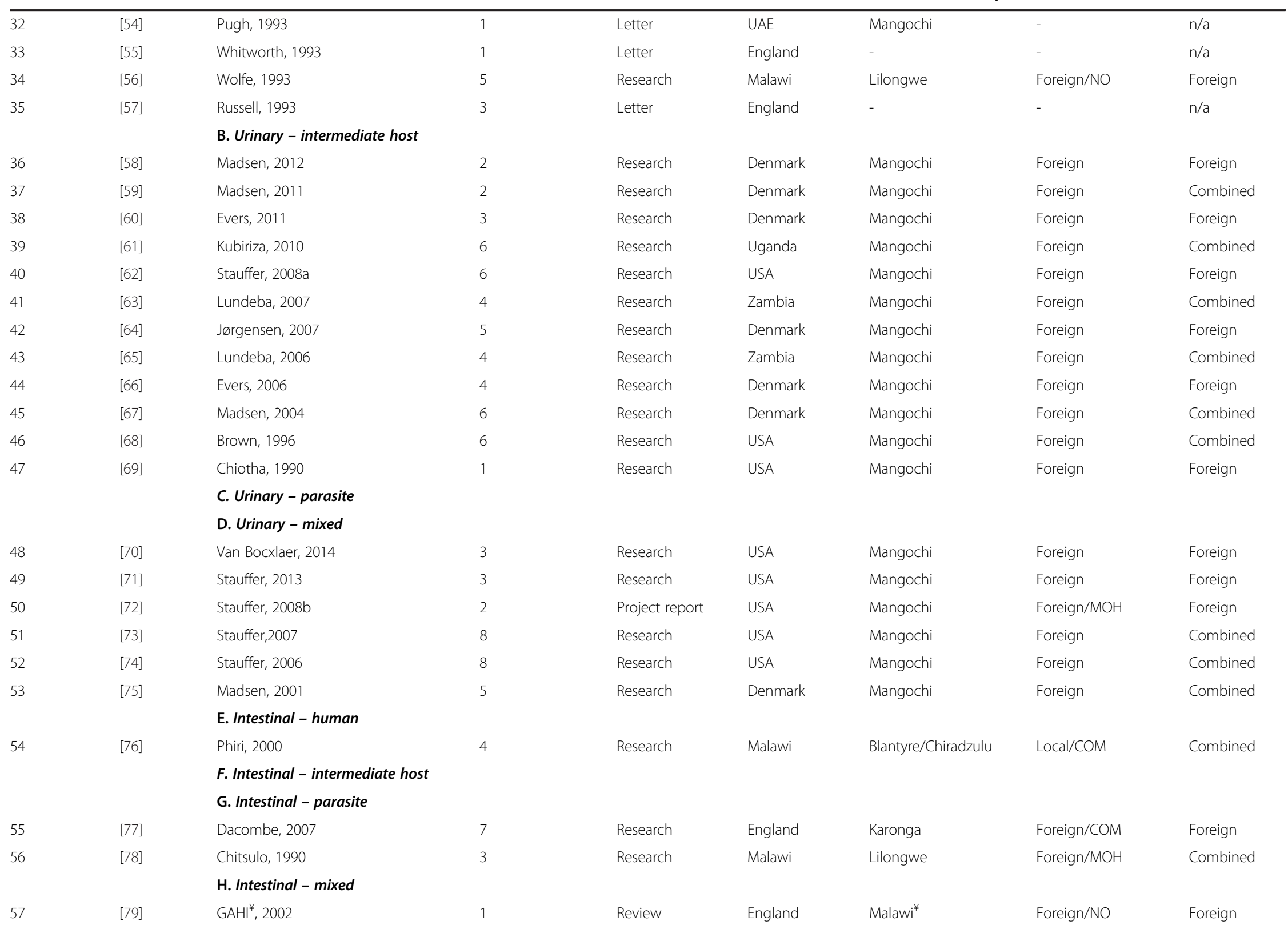


Table 2 Characteristics of schistosomiasis related documents included in the review; The documents have been stratified by area of focus (Continued)

\begin{tabular}{|c|c|c|c|c|c|c|c|c|}
\hline & & I. Both - human & & & & & & \\
\hline 58 & [19] & Teesdale, 1985 & 2 & Review & Malawi & Malawi ${ }^{\S}$ & Foreign & Combined \\
\hline 59 & {$[20]$} & Bowie, 2004 & 5 & Research & Malawi & Malawi $^{\mu}$ & Foreign/MOH & Combined \\
\hline 60 & {$[80]$} & Berezowska, 2012 & 5 & Research & Switzerland & Blantyre/Lilongwe & Foreign/MOH & Combined \\
\hline 61 & [81] & Msyamboza, 2010 & 5 & Research & Malawi & Southern Malawi ${ }^{ \pm}$ & Foreign/MOH & Combined \\
\hline 62 & [82] & Redman, 2010 & 4 & Review & Scotland & Malawi & Foreign & Foreign \\
\hline 63 & [83] & Naus, 2003 & 5 & Research & Netherlands & Blantyre & Foreign/COM & Combined \\
\hline 64 & [84] & Gordon, 2003 & 6 & Research & Malawi & Blantyre & Foreign/COM & Foreign \\
\hline 65 & {$[85]$} & Kayuni, 2003 & 1 & Research & Malawi & Malawi $^{\Omega}$ & Local/COM & Local \\
\hline 66 & {$[86]$} & Bloch, 2003 & 2 & Research & Denmark & Likoma & Foreign/MOH & Combined \\
\hline 67 & [87] & Jackson, 2003 & 3 & Research & England & - & Foreign & Foreign \\
\hline 68 & [88] & Randall, 2002 & 12 & Research & England & Karonga & Foreign/COM & Combined \\
\hline 69 & [89] & Trachtenberg, 2002 & 6 & Research & USA & - & Foreign & Foreign \\
\hline 70 & [90] & Salanitri, 2002 & 3 & Case report & Australia & - & - & $\mathrm{n} / \mathrm{a}$ \\
\hline 71 & [91] & Waldman, 2001 & 4 & Case report & England & - & - & $\mathrm{n} / \mathrm{a}$ \\
\hline 72 & [92] & Cooke, 1999 & 4 & Case report & England & - & - & $\mathrm{n} / \mathrm{a}$ \\
\hline 73 & [93] & Hall, 1999 & 9 & Research & England & Mangochi & Foreign/MOH & Foreign \\
\hline 74 & [94] & MacLachlan, 1997 & 2 & Research & Ireland & Zomba & Foreign/NO & Combined \\
\hline 75 & [95] & Hipgrave, 1997 & 4 & Case report & Australia & - & - & $\mathrm{n} / \mathrm{a}$ \\
\hline 76 & [96] & Jelinek, 1996 & 3 & Case report & Germany & - & - & $\mathrm{n} / \mathrm{a}$ \\
\hline 77 & [97] & Ager, 1996 & 4 & Research & Malawi & Mangochi & Foreign/NO & Combined \\
\hline 78 & [98] & Wiselka, 1993 & 2 & Case report & England & - & - & $\mathrm{n} / \mathrm{a}$ \\
\hline 79 & [99] & Ager, 1992 & 1 & Research & Malawi & Mangochi & Foreign/NO & Foreign \\
\hline \multirow[t]{2}{*}{80} & {$[100]$} & Wolff, 1989 & 2 & Project report & Malawi & Lilongwe/Zomba & Foreign/MOH & Combined \\
\hline & & J. Both - intermediate host & & & USA & Mangochi & Foreign & Foreign \\
\hline 81 & [101] & Stauffer, 2012 & 2 & Research & & & & \\
\hline 82 & [102] & Phiri, 2002 & 1 & Research & Malawi & Mangochi & Foreign & Local \\
\hline \multirow[t]{3}{*}{83} & [103] & Msukwa, 1997 & 1 & Research & Malawi & Mangochi & Foreign & Foreign \\
\hline & & K. Both - parasite & & & & & & \\
\hline & & L. Both - mixed & & & & & Foreign/COM & \\
\hline 84 & [104] & Poole, 2014 & 8 & Research & England & Chikhwawa & & Combined \\
\hline 85 & {$[105]$} & Madsen, 2006 & 6 & Research & Denmark & Mangochi & Foreign & Combined \\
\hline 86 & {$[106]$} & Danida, 2000 & 1 & Project report & Denmark & Mangochi & Foreign/MOH & Foreign \\
\hline
\end{tabular}


Table 2 Characteristics of schistosomiasis related documents included in the review; The documents have been stratified by area of focus (Continued)

\begin{tabular}{llllllll}
\hline 87 & {$[107]$} & Stauffer, 1997 & 8 & Research & USA & Mangochi & Foreign \\
88 & {$[108]$} & Cetron,1996b & 3 & Letter & USA & Lilongwe \\
89 & {$[109]$} & Wiselka, 1988 & 4 & Research & England & Lilongwe & Foreign/NO \\
\hline
\end{tabular}

${ }^{{ }^{B} B l a n t y r e, ~ C h i k h w a w a, ~ C h i r a d z u l u, ~ C h i t i p a, ~ D o w a, ~ K a r o n g a, ~ K a s u n g u, ~ L i l o n g w e, ~ M a c h i n g a, ~ M a n g o c h i, ~ M c h i n j i, ~ M u l a n j e, ~ M w a n z a, ~ M z i m b a, ~ N k h o t a k o t a, ~ N s a n j e, ~ N t c h i s i, ~ P h a l o m b e, ~ R u m p h i, ~ S a l i m a ~ a n d ~ Z o m b a . ~}$

${ }^{\mu}$ Balaka, Chikhwawa, Chitipa, Dedza, Dowa, Kasungu, Lilongwe, Machinga, Mangochi, Mchinji, Mulanje, Mwanza, Mzimba, Nsanje, Ntcheu, Phalombe, Rumphi, Salima, Thyolo and Zomba.

士Blantyre, Chikhwawa, Chiradzulu, Mwanza, Phalombe and Thyolo.

¿Balaka, Chikhwawa, Dedza, Karonga, Mangochi, Mchinji, Mzimba and Thyolo.

₹GAHI (Global Atlas of Helminth Infections): Chitipa, Karonga, Rumphi, Mzimba, Nkhata Bay, Kasungu, Mchinji, Ntchisi, Dowa, Lilongwe, Dedza, Salima, Ntcheu, Mangochi, Balaka, Machinga, Zomba, Blantyre, Chikhwawa, Nsanje and Mulanje.

${ }^{\mathrm{N}} \mathrm{DHO}=$ District Health Office: $\mathrm{COM}=$ College of Medicine: $\mathrm{MOH}=$ Ministry of Health; UNC=University of North Carolina: $\mathrm{NO}=\mathrm{Not}$ Obtained.

amplementing agency: Foreign=only foreign institution involved; Local=only Malawian institution involved; Combined=both foreign and Malawian institution involved; $\mathrm{n} / \mathrm{a}=$ not applicable. 
during the rainy season from December to April and part of the dry season from April to July. Transmission increases in the dry season from May and peaks in October, after which it decreases until the start of the rainy season around December when transmission stops. There may be local deviations in this pattern depending on the degree of wind and wave exposure of the shoreline. In the northern part of the lake, B. nyassanus is not found in shallower water possibly due to frequent strong wave action from June to August [58,66,71,73,101]. Seasonality of transmission in inland waters, beyond Lake Malawi, is caused by cercariae produced in rivers, streams, ponds and canals where B. globosus is the intermediate host; this seems particularly intense during the rainy season and for some time thereafter [66].

While much has been revealed regarding transmission of urinary schistosomiasis in Lake Malawi, not much has been documented about the seasonality of transmission of urinary schistosomiasis external to the lake as well as about transmission of intestinal schistosomiasis in Malawi in general. One study carried out in Mangochi between 2003 and 2007 reported that the intensity of transmission of $S$. haematobium in communities along the lakeshore was high as demonstrated by re-infection rates of 35\% both in Cape Maclear and Msaka after offering mass treatment to school children in the previous year [71].

\section{Environmental aspects of schistosomiasis in Malawi}

The impact of environmental changes affecting most classes of human pathogens has not spared schistosomiasis. The effects of unsafe water and lack of sanitation on the distribution and transmission of schistosomiasis in Malawi have been well documented [21,23,26,29,31,75,80,103]. Several studies have addressed the effects of ecological and environmental changes on the distribution and transmission of schistosomiasis in Malawi [40,57,58,65,69,70,73,100,106]. It has been argued that increasing human population pressure and overfishing have decreased the densities of natural snail-eating fish species in the lake, which in turn has increased the densities of intermediate host species and, subsequently, the transmission of S. haematobium. Moreover, it has been argued that weather conditions, in terms of rain, wind, temperature, rainfall, lake level and wave action in the lake, have a strong influence on intermediate host densities and transmission of the infection $[60,66,71,74,101]$.

\section{Geographical distribution of schistosomiasis in Malawi}

The prevalence of schistosomiasis varies according to the distribution of intermediate hosts and schistosome parasites in water bodies and according to the behavioural patterns of humans. In order to determine the distribution of schistosomiasis in Malawi, the reviewed articles were linked to districts where initial research was carried out.
From the 89 articles reviewed, 63 (71\%) mentioned at least one specific district linked to their field or laboratory work. Figure 3 illustrates how these studies were distributed across Malawi. Mangochi was the most commonly mentioned district, with 40 references; 10 references each related to Lilongwe and Blantyre, 7 references related to Chikhwawa, 6 references related to Zomba, 4 references each related to Karonga, Mchinji, Salima and Mzimba, 3 references each related to Chiradzulu, Chitipa, Dowa, Kasungu, Machinga, Dedza, Balaka, Nsanje and Rumphi, 2 references each related to Mwanza, Phalombe, Thyolo, Mulanje, Ntcheu, Ntchisi and Nkhotakota, and one reference related to Likoma.

A total of 27 districts across Malawi were target sites for 33 studies dealing with the two forms of schistosomiasis during the period under review (Figure 3). Five districts comprising Mangochi, Blantyre, Chikhwawa, Zomba and Salima were target sites for 27 studies exclusively addressing urinary schistosomiasis, and 4 districts comprising Karonga, Lilongwe, Blantyre and Chiradzulu were target sites for 3 studies, which exclusively addressed intestinal schistosomiasis. One project collated and mapped (on its website) data related to the prevalence of $S$. haematobium, S. mansoni, schistosomiasis (both S. haematobium and S. mansoni), blood in urine, and soil transmitted helminths (STHs) produced by various surveys around the world [78]. This project successfully reported on the distributions of S. haematobium, S. mansoni, schistosomiasis and STHs in Malawi from 37 surveys carried out between 1982 and 2002 (and included in this review, if eligible). There was nothing reported from Malawi on blood in urine.

A total of 26 field surveys involving 25 districts were carried out to estimate infection prevalence rates at different times during the years between 1988 and mid 2014 . For human infections with S. haematobium, 16 (62\%) field surveys were carried out. All of these studies reported at least one infected individual, regardless of geographical area surveyed, and further observed infection prevalence rates ranging from $0.6 \%$ to $94.9 \%$ for $S$. haematobium. For human infections with S. mansoni, 3 (11\%) field surveys were carried out in Mangochi, Blantyre and Chiradzulu, and the authors reported prevalence rates ranging from $0 \%$ to $2.1 \%$. The remaining 7 (27\%) surveys combined human infections with both S. haematobium and S. mansoni, and they reported infection prevalence rates ranging from $2.0 \%$ to $94.5 \%$ and from $0 \%$ to $67.0 \%$, respectively, in the northern highlands, central lowlands, southern lowlands, urban areas, Chikhwawa and Chizumulu Island. These survey findings suggest that urinary schistosomiasis is more common and widely distributed in Malawi, and thus comprise a larger public health problem, than intestinal schistosomiasis [21,23,26,31,75,78,103].

Among the 22 field studies from where these findings originate, 11 (50\%) were carried out in schools, 8 (36\%) 


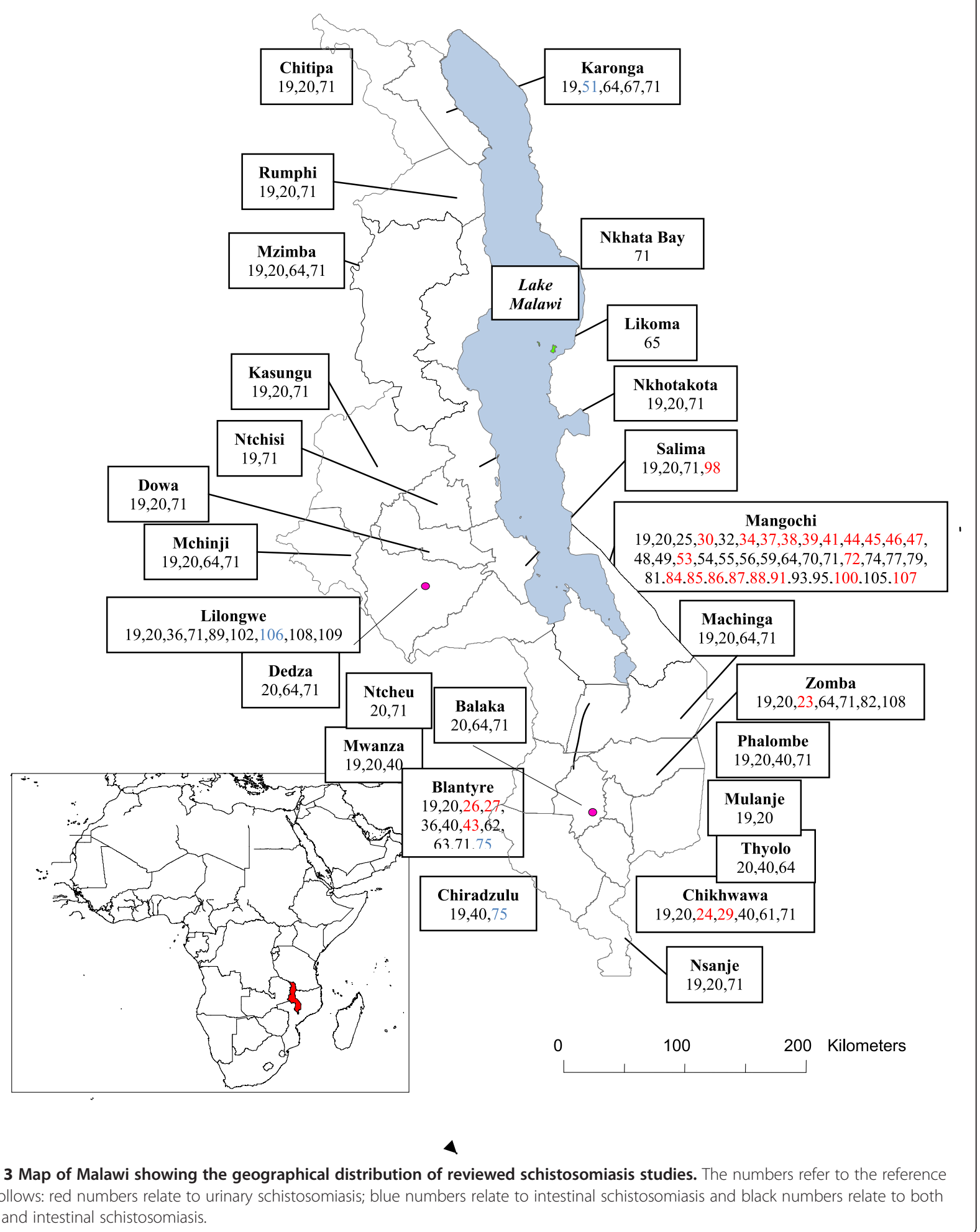

Figure 3 Map of Malawi showing the geographical distribution of reviewed schistosomiasis studies. The numbers refer to the reference list as follows: red numbers relate to urinary schistosomiasis; blue numbers 
were carried out in communities and 3 (14\%) were carried out in both schools and communities. The highest infection rates for S. haematobium were observed in the southern lowland districts of Mangochi, Phalombe and Chikhwawa, while the lowest infection rates were observed in the central highland district of Lilongwe and southern highland districts of Mwanza and Thyolo. For S. mansoni, the highest infection rates were observed in the central plains of Lilongwe, rural Chiradzulu and southern lowland district of Chikhwawa, and the lowest infection rates were found in the northern highlands, Likoma and Chizumulu Islands, central lowlands, urban districts of Mzuzu, Lilongwe and Blantyre, southern lakeshore district of Mangochi and in southern highlands. The details and a summary of the infection prevalence surveys carried out across Malawi during the period under review are shown in Table 3.

\section{Schistosomiasis prevention and control in Malawi}

The history of schistosomiasis prevention and control efforts in Malawi dates back to the 1960s when the development of water resources prompted initiation of schistosomiasis control schemes [19]. The establishment of these schemes formed the basis for surveys estimating the magnitude and distribution of schistosomiasis in the country. The findings of these surveys led to the formation of the NSCP in the Ministry of Health. Between 1978 and 1990s, the NSCP conducted a number of nationwide prevalence surveys, confirming the widespread distribution of $S$. haematobium and $S$. mansoni in Malawi $[19,99,108]$.

The NSCP has since been implementing centralized and vertical schistosomiasis prevention and control, characterized mainly by regular chemotherapy and health education in schools and villages [99]. In the new millennium, the NSCP has changed the strategy in several steps by decentralizing interventions, making efforts to bring on board STHs and further integrating control efforts with the NTDs as well as School Health and Nutrition (SHN) programs [9]. Moreover, there have been deliberate efforts to integrate schistosomiasis and STH prevention and control efforts within district implementation plans (DIPs) to strengthen local ownership and improve sustainability. Districts have been delivering treatments against both schistosomiasis and STHs in schools and communities during annual Child Health Day (CHD) campaigns.

An appraisal of 14 studies reporting from 21 surveys carried out to estimate the prevalence rates of schistosomiasis at different locations during the period between 1988 and 2014, revealed that the average prevalence rates of urinary schistosomiasis were $24.0 \%$ using the filtration method, $21.7 \%$ using the sedimentation method and $58.7 \%$ using serological methods, while intestinal schistosomiasis prevalence rates averaged $2.8 \%$ using the
Kato Katz method and 0.7\% using the Formol Ether Concentration method, as summarized in Table 4.

One study carried out in Mangochi in 1996 [41] investigated the occurrence of female genital schistosomiasis (FGS) amongst women infected with S. haematobium. It was found that $65 \%$ of the infected women had ova in the cervix, vagina or/and vulva by microscopy of genital biopsies; of which $76 \%$ were confirmed to have genital infection using colposcopic examinations. Associations have been observed between the incidence of FGS and HIV amongst women infected with S. haematobium; these women may be exposed to an additional risk of HIV transmission to or from their partners $[27,47]$.

\section{Schistosomiasis and tourism in Malawi}

As one of Malawi's main tourist destinations, Lake Malawi, has frequently been cited as a possible source of contracting schistosomiasis $[45,46,48,51,53-56,107]$. While few documents mention any specific locations where tourists had contracted schistosomiasis, the popular tourist destination districts of Mangochi and Salima were mentioned as some of the places infested with the disease. However, due to lack of systematic monitoring of schistosomiasis transmission in Lake Malawi, and a lack of evidence about specific transmission sites, would-be visitors and tourists to Malawi have been warned about getting in touch with any natural water bodies whilst in the country $[45,55,104]$. Of the 89 reviewed documents, 22 (25\%) reported on individuals who had developed signs and symptoms of schistosomiasis after returning from a visit to Malawi. These documents comprised 13 case reports and 9 letters to the editor written by non-Malawian authors [25,30,33-40,46-56,89-91,94,95,97,107].

\section{Discussion}

We identified 89 documents on schistosomiasis in Malawi published since 1985, and there is a noticeable increase in the quantity of available literature as compared with the last review in 1985 [19], which mainly relied on unpublished survey data collected by the Ministry of Health across the country between 1976 and 1983. On average, 3 documents were produced per year since 1985, signifying an increase in interest in the schistosomiasis topic by researchers from both within and outside Malawi. Similarly, there was an increase in the number of both Malawian and non-Malawian authors involved in writing these documents. This finding suggests an increased capacity and ability to undertake research on schistosomiasis in Malawi.

The reviewed literature revealed that urinary schistosomiasis receives much more attention by the scientific community as compared with intestinal schistosomiasis. Thus, $97 \%$ of the reviewed documents included urinary schistosomiasis, whereas only $40 \%$ covered at least one 
Table 3 Schistosomiasis prevalence studies carried out in Malawi between 1988 and mid 2014

\begin{tabular}{|c|c|c|c|c|c|c|c|}
\hline $\begin{array}{l}\text { Reference } \\
\text { number }\end{array}$ & $\begin{array}{l}\text { Year study } \\
\text { was done }\end{array}$ & $\begin{array}{l}\text { Place where } \\
\text { study was done }\end{array}$ & $\begin{array}{l}\text { Sample } \\
\text { size }\end{array}$ & $\begin{array}{l}\text { Target group } \\
\text { examined }\end{array}$ & $\begin{array}{l}\text { Diagnostic } \\
\text { technique used }\end{array}$ & $\begin{array}{l}\text { Infection species } \\
\text { targeted }\end{array}$ & Prevalence (\%) \\
\hline [20] & 2003 & North high* & 257 & School children & Filtration & S. haematobium & 7.4 \\
\hline [20] & 2003 & North high & 257 & School children & Kato Katz & S. mansoni & 0 \\
\hline [20] & 2003 & Centre high $^{\alpha}$ & 242 & School children & Filtration & S. haematobium & 2.0 \\
\hline [20] & 2003 & Centre low ${ }^{\S}$ & 291 & School children & Filtration & S. haematobium & 9.5 \\
\hline [20] & 2003 & Centre low & 291 & School children & Kato Katz & S. mansoni & 0 \\
\hline [20] & 2003 & South high ${ }^{\Omega}$ & 261 & School children & Filtration & S. haematobium & 3.2 \\
\hline [20] & 2003 & South high & 261 & School children & Kato Katz & S. mansoni & 1.3 \\
\hline [20] & 2003 & South low ${ }^{ \pm}$ & 297 & School children & Filtration & S. haematobium & 23.2 \\
\hline [20] & 2003 & South low & 297 & School children & Kato Katz & S. mansoni & 0 \\
\hline [20] & 2003 & Urban $^{\mu}$ & 277 & School children & Filtration & S. haematobium & 3.4 \\
\hline [20] & 2003 & Urban & 277 & School children & Kato Katz & S. mansoni & 0 \\
\hline [23] & 2014 & Zomba & 483 & School age children & Filtration & S. haematobium & 34.0 \\
\hline [103] & 2014 & Chikhwawa & 165 & Mothers & Filtration & S. haematobium & 45.1 \\
\hline [103] & 2014 & Chikhwawa & 208 & Pre-school children & Filtration & S. haematobium & 17.7 \\
\hline [103] & 2014 & Chikhwawa & 165 & Mothers & Serology & S. haematobium & 94.5 \\
\hline [103] & 2014 & Chikhwawa & 208 & Pre-school children & Serology & S. haematobium & 49.5 \\
\hline [103] & 2014 & Chikhwawa & 84 & Mothers & Kato Katz & S. mansoni & 21.5 \\
\hline [103] & 2014 & Chikhwawa & 102 & Pre-school children & Kato Katz & S. mansoni & 0 \\
\hline [26] & 2012 & Chikhwawa & 1642 & Community based & Sedimentation & S. haematobium & 14.2 \\
\hline [26] & 2012 & Chikhwawa & 1642 & Community based & Kato Katz & S. mansoni & 4.3 \\
\hline [29] & 2012 & Mangochi & 400 & School children & Filtration & S. haematobium & 12.5 \\
\hline [58] & 1999 & Mangochi & 4324 & Community based & Filtration & S. haematobium & 39.0 \\
\hline [58] & 1999 & Mangochi & 4131 & School children & Filtration & S. haematobium & 64.5 \\
\hline [80] & 2008 & Blantyre & 14 & Community based & Sedimentation & S. haematobium & 28.6 \\
\hline [80] & 2008 & Chikhwawa & 140 & Community based & Sedimentation & S. haematobium & 5.7 \\
\hline [80] & 2008 & Chiradzulu & 178 & Community based & Sedimentation & S. haematobium & 5.6 \\
\hline [80] & 2008 & Mwanza & 128 & Community based & Sedimentation & S. haematobium & 0.8 \\
\hline [80] & 2008 & Phalombe & 39 & Community based & Sedimentation & S. haematobium & 94.9 \\
\hline$[80]$ & 2008 & Thyolo & 55 & Community based & Sedimentation & S. haematobium & 1.8 \\
\hline [31] & 2006 & Blantyre & 1145 & School children & Filtration & S. haematobium & 10.4 \\
\hline [32] & 1998 & Mangochi & 1084 & School children & Filtration & S. haematobium & 33.5 \\
\hline [32] & 2007 & Mangochi & 1084 & School children & Filtration & S. haematobium & 4.5 \\
\hline [71] & 2003 & Mangochi & 455 & School children & Filtration & S. haematobium & 36.5 \\
\hline [71] & 2004 & Mangochi & 745 & School children & Filtration & S. haematobium & 35.7 \\
\hline [71] & 2004 & Mangochi & 75 & School children & Serology & S. haematobium & 70.7 \\
\hline [71] & 2005 & Mangochi & 1066 & School children & Filtration & S. haematobium & 21.9 \\
\hline [71] & 2005 & Mangochi & 55 & School children & Serology & S. haematobium & 50.9 \\
\hline [71] & 2006 & Mangochi & 1204 & School children & Filtration & S. haematobium & 36.4 \\
\hline [71] & 2007 & Mangochi & 1100 & School children & Filtration & S. haematobium & 23.7 \\
\hline [85] & 2003 & Likoma & 339 & Community based & Filtration & S. haematobium & 27.1 \\
\hline [85] & 2003 & Likoma & 204 & Community based & Kato Katz & S. mansoni & 0.5 \\
\hline [85] & 2003 & Chizumulu & 123 & Community based & Filtration & S. haematobium & 30.1 \\
\hline [85] & 2003 & Chizumulu & 108 & Community based & Kato Katz & S. mansoni & 0 \\
\hline
\end{tabular}


Table 3 Schistosomiasis prevalence studies carried out in Malawi between 1988 and mid 2014 (Continued)

\begin{tabular}{|c|c|c|c|c|c|c|c|}
\hline [85] & 2006 & Likoma & 392 & School children & Filtration & S. haematobium & 30.0 \\
\hline [105] & 1999 & Mangochi & 609 & School children & Kato Katz & S. mansoni & 0 \\
\hline [105] & 1999 & Mangochi & 421 & Community based & Kato Katz & S. mansoni & 2.1 \\
\hline [105] & 2000 & Mangochi & 4131 & School children & Filtration & S. haematobium & 23.8 \\
\hline [105] & 2000 & Mangochi & 2316 & Community based & Filtration & S. haematobium & 17.2 \\
\hline$[75]$ & 2000 & Blantyre & 273 & Village children & $\mathrm{FEC}^{\beta}$ & S. mansoni & 0 \\
\hline [75] & 2000 & Chiradzulu & 280 & Village children & FEC & S. mansoni & 0.7 \\
\hline [45] & 1993 & Lilongwe & 955 & Expatriates & Serology & S. haematobium & 32.0 \\
\hline [108] & 1988 & Lilongwe & 165 & Village children & Sedimentation & S. haematobium & 0.6 \\
\hline [108] & 1988 & Lilongwe & 165 & Village children & Kato Katz & S. mansoni & 67.0 \\
\hline
\end{tabular}

${ }^{*}$ Chitipa, Rumphi and Mzimba; ${ }^{a}$ Ntcheu, Dedza, Dowa, Kasungu, Mchinji and Ntchisi; ${ }^{5}$ Salima and Nkhotakota; ${ }^{\Omega}$ Phalombe, Mulanje, Thyolo, Mwanza and Balaka;

${ }^{ \pm}$Nsanje, Chikwawa, Mangochi, Machinga; ${ }^{\mu} \mathrm{Mzuzu}$, Lilongwe and Blantyre; ${ }^{\beta} \mathrm{FEC}=$ Formol Ether Concentration.

aspect of intestinal schistosomiasis; more than one third included both forms of schistosomiasis and only 3 documents exclusively addressed intestinal schistosomiasis. This finding may be explained by the observation that urinary schistosomiasis is more common and widely distributed in Malawi and thus comprises a larger public health problem than intestinal schistosomiasis $[20,23,26,31,103]$. It may also be explained by the observation that urinary schistosomiasis is common in the major tourist destinations around Lake Malawi and thus receives substantial international attention $[25,28,30,36,39,45,46,55,91,97]$; this may further explain the observation that the human aspects of urinary schistosomiasis receive more attention than other aspects of the infection [110]. For urinary schistosomiasis, more than two thirds of the reviewed documents covered aspects of the definitive human host, whereas less than a quarter of the documents addressed the intermediate host and none addressed the parasite itself. This apparent bias may relate to the limited resources available for schistosomiasis research. However, it might still be argued that non-human aspects of urinary (and intestinal) schistosomiasis need to be carefully studied to identify transmission sites and describe transmission intensities and patterns, seasonality and other determinants of infection of importance to prevention and control efforts [21].

Most of the articles under review were published between the years 1995 to 2010, including the period in the mid 90s when reporting began in the international media about the potential health hazard associated with visiting Malawi and about the linkages between water bodies, particularly Lake Malawi, and the scourge of schistosomiasis amongst tourists returning from visits to Malawi [36,39,45,46,48,51,53-56,91,97,107]. Much of the research and publications that followed arose from reactions by the Government of Malawi and its international partners to the concerns raised by this international outcry on the schistosomiasis problem in the country. The response saw several international research institutions with or without partnering local institutions venturing into research in this field.

The reviewed literature revealed that almost half of the research institutions involved were foreign and that half of these operated through partnerships with local research institutions. It also revealed that almost all $(98 \%)$ of the research carried out on schistosomiasis in Malawi was funded by foreign agencies. The typical

Table 4 Summary of schistosomiasis prevalence surveys done in Malawi between 1988 and mid 2014

\begin{tabular}{|c|c|c|c|c|c|c|c|c|}
\hline \multirow{2}{*}{$\begin{array}{l}\text { Infection } \\
\text { form }\end{array}$} & \multicolumn{3}{|c|}{ Where surveys were done } & \multirow[t]{2}{*}{ Total } & \multirow{2}{*}{$\begin{array}{l}\text { Diagnostic } \\
\text { technique } \\
\text { used }\end{array}$} & \multirow{2}{*}{$\begin{array}{l}\text { No. of } \\
\text { surveys* }\end{array}$} & \multicolumn{2}{|l|}{ Prevalence (\%) } \\
\hline & School & Community & $\overline{\text { Combined }}$ & & & & Mean (range) & Median \\
\hline \multirow[t]{3}{*}{ Urinary } & 10 & 3 & 2 & 15 & Filtration & 16 & $23.7(2.0-64.5)$ & 23.7 \\
\hline & & & & & Sedimentation & 3 & $19.0(0.6-94.9)$ & 5.7 \\
\hline & & & & & Serology & 4 & $59.5(32.0-94.5)$ & 50.9 \\
\hline \multirow[t]{2}{*}{ Intestinal } & 0 & 1 & 1 & 2 & Kato Katz & 6 & $7.4(0-67.0)$ & 0 \\
\hline & & & & & $\mathrm{FEC}^{\beta}$ & 1 & $0.7(0-4.3)$ & 0 \\
\hline Both & 1 & 4 & 0 & 5 & - & - & - & - \\
\hline Total & 11 & 8 & 3 & 22 & - & - & - & - \\
\hline
\end{tabular}

*Some surveys used more than one diagnostic method; ${ }^{\beta}$ Formol Ether Concentration. 
arrangement was that local partner institutions contributed in kind support by providing personnel and equipment, while international partners provided funds. Both partners provided skills and expertise. Even though the schistosomiasis challenge is more of a local public health problem than a problem for foreigners, local funding for its research is almost non-existent. The numbers of Malawian first authors and their corresponding research institutions have not significantly increased during the period under review. This is somewhat paradoxical, considering that all our observations indicate that the concerns, subsequent research and ensued publications on schistosomiasis during the period under review were more foreign driven than local. Therefore, it would be appropriate for the Government of Malawi through relevant regulatory institutions to engage in discussions with international scientists and institutions about research capacity strengthening and collaboration in this important field.

There was almost no documentation produced exclusively by local researchers and research institutions on the risks and health consequences of contracting schistosomiasis in any water bodies in Malawi. It may be a lack of local attention to transmission dynamics and morbidity of infection that has attracted foreign research interests in this field. Most articles by foreign-based authors confirmed the existence of a risk of contracting schistosomiasis if exposed to Malawian water bodies, particularly Lake Malawi. This aspect has been discerned from published case studies involving some of the visitors who had been to Malawi and later developed symptoms of contracting the disease [25,28,30,33,35,36,38-40,46,51,55,81,91]. Furthermore, we observed that research on schistosomiasis has not been evenly distributed geographically across the country. Some locations, such as Mangochi, Lilongwe, Blantyre and Chikhwawa, have been given higher priority by researchers than others. These biases make it difficult to draw any meaningful conclusions regarding the nationwide distribution and transmission of schistosomiasis in Malawi [111].

This review reaffirmed previous observations that $S$. haematobium for urinary schistosomiasis and S. mansoni for intestinal schistosomiasis are the dominant species of schistosomes infecting humans in Malawi. Moreover, important intermediate host species for infections with $S$. haematobium and S. mansoni are Bulinus globosus and Biomphalaria pfeifferi, respectively [61,67,72,74,78,101,103,108]. However, another intermediate host species (Bulinus nyassanus) for $S$. haematobium was recently discovered [74]. This intermediate host appears to be responsible for much of the transmission that takes place in the lake waters along the beaches of Lake Malawi [74]. There is limited knowledge available on intermediate host species in most parts of Malawi other than Lake
Malawi, because relatively few sites have undergone careful investigations, particularly of the intermediate host. As such, there is much to be done in terms of describing transmission dynamics on a wider geographical scale. One way forward is to institute widespread community-based transmission monitoring of the infection using trained environmental health workers or community volunteers across the country.

Prevalence studies carried out in selected locations nationwide between 1988 and 2014 revealed substantial variation in the prevalence of both S. haematobium and $S$. mansoni [20,23,26,29,31,32,45,58,71,75,80,85,103,105,108]. Some of this variation is caused by differences in distribution and transmission, and some is caused by differences in methodologies used in various studies. Methodological differences among studies carried out in different locations negate making meaningful comparisons of the findings. Nevertheless, prevalence estimates over the period under review appear to decline or stabilize in some locations, such as Mangochi, Likoma, Phalombe, Zomba and Chikhwawa; and some estimates have shown that the infection has remained low in locations such as Blantyre, Thyolo, Mwanza and Chiradzulu $[20,23,26,31,32,80,99,103,105]$. However, one study observed relatively high re-infection rates (of $\sim 35 \%$ ) with urinary schistosomiasis in selected lake-shore communities when re-examining the same children parasitologically 12 months after offering mass drug administration to highrisk groups [71]. This observation suggests that the transmission intensity at the community level has remained high and calls for long-term intervention and increased attention to optimized coverage in treatment campaigns.

Some studies from Malawi have addressed the relationship between schistosomiasis and associated conditions. One study observed that there is a high prevalence of female genital schistosomiasis (FGS) amongst women infected with $S$. haematobium and that this puts the women and their sexual partners at high risk of contracting HIV-infection. Consequently, this might have implications for marital and sexual life of the affected women $[27,41]$. Another study carried out during the period under review has shed more light on several environmental factors such as human activity, wind and wave action, temperature, rainfall, lake level and density of intermediate hosts, which impact the distribution and prevalence of schistosomiasis in Malawi by influencing whether the life cycle of schistosomiasis can be completed or not [112]. Proper understanding of these relationships between schistosomiasis and associated conditions will go a long way in helping to inform future prevention and control strategies in Malawi.

Previously, schistosomiasis treatment, prevention and control program activities in Malawi through the NSCP were centralized and specific to a single disease. However, 
currently there have been deliberate efforts to decentralize and integrate schistosomiasis prevention and control efforts with those of STHs using the strategies recommended by WHO for the prevention and control of NTDs $[1,18,113]$. This is expected to provide synergistic effects of treatment efforts for both schistosomiasis and STHs within the overall context of NTDs [114]. Engaging district teams is expected to strengthen local ownership and improve sustainability. The NSCP operates with support from international partners, such as World Vision International, Merck, WHO, the Department for International Development (DfID), through the Integrated Control of Schistosomiasis in sub-Saharan Africa (ICOSA). Since 2009, the ICOSA project has been implementing a strategy to scale-up treatment by reaching over 5.6 million people from all over Malawi. Schistosomiasis and STHs treatment campaigns are carried out annually using Mass Drug Administration (MDA) offered by health workers through schools and communities. There is a need to further integrate these treatment campaigns with other ongoing programs, such as the expanded program for immunizations (EPI), maternal and child health $(\mathrm{MCH})$, and other similar routes for distribution of drugs such as the WHO recommended community-directed intervention (CDI) approach, in order to reach other high risk groups, such as pre-school and out-of-school children [115].

In more than three of four studies reviewed, ethical clearance had been sought from the Ministry of Health's NHSRC or the University of Malawi's COMREC prior to execution of their research. The NHSRC, COMREC and the newly formed National Committee on Research in the Social Sciences and Humanities (NCRSH), which refer to the mother statutory entity, known as the National Commission for Science and Technology (NCST), have an overall mandate to promote, support, coordinate and regulate the development and application of research, science and technology in Malawi. However, from the present review, there appears to be some level of inconsistency about where researchers apply for ethical clearance for their research proposals in Malawi. Thus, 24\% of the reviewed research studies appeared not to have sought any ethical clearance or to have obtained it from ineligible offices. There is a dire need for more coordination amongst these three entities under the 'umbrella' of the NCST to ensure that health research is not duplicative and is focused on areas that are in line with national priorities and also to ensure that schistosomiasis research, prevention and control are given much needed political priority as a public investment $[9,116]$.

There is a relationship between the widely publicized schistosomiasis problem and the crisis of the tourism industry in Malawi [25,46,51,117]. The Malawi Government considers tourism to be a prime contributor to the country's economy. This is outlined in the country's strategic papers for attainment of the Millennium Development Goals and most recently in the Economic Recovery Plan (ERP) of 2012. For visitors who make it to the lake, there is no trustworthy information about the risk of transmission of schistosomiasis around lakeshore resorts and beyond. Therefore, there is an urgent and a strong local and national need for conducting systematic investigations of the seasonal transmission dynamics of urinary schistosomiasis in the lakeshore resorts around Lake Malawi and to build local institutional and human capacity in this highly specialized discipline.

While it is generally acknowledged that both forms of schistosomiasis are prevalent in Malawi, there is inadequate documentation about the transmission patterns at the local level to make sound judgements and statements about the risks of contracting infection in most communities and tourist resorts. Even where some research has been done, seasonality of transmission of schistosomiasis varies according to environmental, geographical, biological and behavioural factors [21,112]. This situation has made it difficult for public health authorities to answer questions from members of the tourist sector, civil society organizations and other agencies regarding the safety of Malawian water bodies from contracting schistosomiasis. There is thus a need for a comprehensive strategy for nationwide monitoring of schistosomiasis distribution and transmission, which includes, among other things, the establishment of an efficient management and information system for schistosomiasis research and knowledge generated by key stakeholders, such as the relevant government departments, researchers, academia, tourist industry as well as international partners. This focus may be aligned with the Global Atlas of Helminth Infections' 'This Wormy World Project' based at the London School of Hygiene and Tropical Medicine in the United Kingdom. [78].

This review has exposed the following knowledge gaps and possible areas for future research and research governance regarding schistosomiasis in Malawi:

1) Distribution and transmission of urinary and intestinal schistosomiasis in Malawi

- There is a need for a deliberate national research policy and strategy to ensure that schistosomiasis research is extended to the many locations not yet covered. This approach will create new and important knowledge on the geographical distribution and transmission of schistosomiasis in Malawi.

- There is a need for a deliberate national effort to ensure that research on the geographical distribution and transmission of intestinal schistosomiasis receives more attention. This will 
address current imbalances in the knowledge of disease epidemiology between urinary and intestinal schistosomiasis within Malawi.

- There is a need for more research focusing on the agents and intermediate hosts of $S$. haematobium and S. mansoni. This will address current imbalances in the level of knowledge about schistosomiasis intermediate hosts, agents and humans hosts in Malawi.

- There is further need for research to investigate the magnitude of the FGS problem in women infected with urinary schistosomiasis and how this relates to transmission of HIV between women and their sexual partners in Malawi.

2) Efficacy and effectiveness of applied prevention and control strategies

- There is a need to ensure that schistosomiasis research is integrated within the overall NSCP approach, as part of surveillance, monitoring and evaluation efforts. This will optimize research coordination and improve knowledge management on the efficacy and effectiveness of schistosomiasis prevention and control in Malawi.

- There is a need for adopting a multidisciplinary and integrated research approach by promoting the involvement of disciplines such as social, behavioural and biological sciences. This will contribute to a more detailed understanding of the disease and its determinants, and thus inform the development of more effective policies and strategies for the prevention and control of schistosomiasis in Malawi.

- There is a need for the NCST through its affiliates NHSRC, NCRSH and COMREC to provide necessary framework for discussing, coordinating and prioritizing health research in Malawi and to ensure that schistosomiasis research, prevention and control are given much needed political priority.

3) Determinants of effectiveness of community-driven prevention and control

- There is a need for more effectively engaging and empowering communities in the fight against schistosomiasis. This will support current NSCP decentralization processes whereby districts are empowered to integrate prevention and control activities in the District Implementation Plans.

4) Establishment of comprehensive nationwide monitoring and surveillance of schistosomiasis

- There is a need for setting up sentinel sites across the country for continued schistosomiasis transmission monitoring and surveillance. This will ensure continued availability of information on the distribution, locality and seasonality of schistosomiasis transmission in high-risk communities and tourist resorts. Moreover, it will involve training of local community members and health extension workers on how to collect, analyze and interpret data for decision making regarding prevention and control interventions at the local level in Malawi.

- There is a need for active involvement of the private sector. Such an approach would contribute to the sustainability of sentinel sites if they are operated on a demand-driven basis, as a service to clients, such as resort operators who have a strong interest in documenting transmission risks within the catchment areas of their resorts.

A strength of this review is that literature searches involved three comprehensive databases and followed up with iterative searches of bibliographies of identified documents for both published and unpublished reports. A possible limitation might be that we have relied on online searches and may thus have missed some hardcopy documents in libraries or offices. Moreover, the decision to exclude documents that were not written in English may have excluded some documents from being reviewed here. Nonetheless, in our opinion, this is a comprehensive systematic review, which provides valuable updated information about schistosomiasis in Malawi.

\section{Conclusion}

This article reviews documentation about schistosomiasis in Malawi that has accumulated since 1985, which is the last time a similar review was published. While confirming the existence of the infection in Malawi, this documentation, however, has failed answering the frequently asked question regarding the safety of local water bodies from schistosomiasis. This limitation relates to poor geographical coverage of research efforts and a lack of deliberate policies and strategies for nationwide surveillance of transmission. While the capacity to conduct schistosomiasis research is available in Malawi, prevention and control efforts are suffering from limited funding and poor coordination amongst key stakeholders. Successes in schistosomiasis control in Malawi rely on intensified communication between researchers and public health professionals, and on increased commitment to surveillance and knowledge management as well as to prevention and control efforts supported by informed policies, strategies and administrative structures at the national, district and community levels. 


\section{Competing interests}

The authors declare that they have no competing interests.

\section{Authors' contributions}

PM and JRS conceived the idea conducted the literature searches. PM, JRS, ASM, SK, SJ and PB reviewed and analyzed the documents, participated in writing and approved the final manuscript.

\section{Acknowledgements}

We would like to thank the authors whose documents have been used in this review. We are grateful to the College of Medicine, Malawi for allowing us to use their facilities to conduct online literature searches for some of the documents used in this review. Finally, we are grateful for the many useful comments and suggestions provided by the reviewers.

\section{Author details}

${ }^{1}$ Research for Health Environment and Development, P.O. Box 345, Mangochi, Malawi. ${ }^{2}$ School of Public Health and Family Medicine, Department of Public Health, College of Medicine, University of Malawi, Private Bag 360, Chichiri, Blantyre 3, Malawi. ${ }^{3}$ Medical Aid Society of Malawi (MASM) Medi Clinics, P.O. Box 1254, Blantyre, Malawi. ${ }^{4}$ Ministry of Health, P.O. Box 30377, Capital City, Lilongwe 3, Malawi. ${ }^{5}$ Steno Health Promotion Center, Steno Diabetes Center, Niels Steensens Vej 8, DK-2820 Gentofte, Denmark.

Received: 15 August 2014 Accepted: 25 November 2014

Published online: 10 December 2014

\section{References}

1. World Health Organization: Sustaining the drive to overcome the global impact of neglected tropical diseases: second WHO report on neglected diseases. Geneva, Switzerland: WHO/HTM/NTD/2013.1; 2013.

2. Molyneux DH: The 'Neglected Tropical Diseases': now a brand identity; responsibilities, context and promise. Parasit Vectors 2012, 5:23.

3. World Health Organization: Changing History. The World Health Report. Geneva, Switzerland: World Health Organization; 2004.

4. World Health Organization: Schistosomiasis: progress report 2001-2011 and strategic plan 2012-2020. Geneva, Switzerland: WHO/HTM/NTD/PCT/2012.7; 2012.

5. World Health Organization: Prevention and control of schistosomiasis and soil transmitted helminthiasis: report of a WHO expert committee. WHO Tech Rep Ser 2002, 912:1-57.

6. Utzinger J, Keiser J: Schistosomiasis and soil-transmitted helminthiasis: common drugs for treatment and control. Expert Opin Pharmacother 2004, 5:263-285.

7. Chitsulo L, Engels D, Montresor A, Savioli L: The global status of schistosomiasis and its control. Acta Trop 2000, 77:41-51.

8. King CH, Dickman K, Tisch DJ: Reassessment of the cost of chronic helminths infection: a meta-analysis of disability-related outcomes in endemic schistosomiasis. Lancet 2005, 365:1561-1569.

9. Stothard JR, Chitsulo L, Kristnsen TK, Utzinger J: Control of schistosomiasis in sub-Saharan Africa: progress made, new opportunities and remaining challenges. Parasitology 2009, 136:1665-1675. doi:10.1017/S00131182009991272.

10. Woolhouse MEJ: Patterns in parasite epidemiology: the peak shift. Parasitol Today 1998, 14:428-434.

11. Jordan P, Webbe G, Sturrock RF: Human schistosomiasis. Wallingford, Oxfordshire: CAB International; 1993.

12. Stothard JR, Sousa-Figueredo JC, Betson M, Bustinduy A, Reinhard-Rupp J: Schistosomiasis in African infants and preschool children: let them be treated! Trends Parasitol 2013, 29:197-205.

13. Tanner M: Evaluation of public health impact of schistosomiasis. Trop Med Parasitol 1989, 40:143-148.

14. Weisbrod BA, Andreano RL, Baldwin RE, Epstein EH, Kelley AC: Disease and economic development: impact of parasitic diseases in St. Lucia. Madison, WI: University of Wisconsin Press; 1973.

15. Nokes C, McGarvey ST, Shiue L, Wu G, Wu H, Bundy DAP, Olds GR: Evidence for an improvement in cognitive function following treatment of Schistosoma japonicum infection in Chinese primary school children. Am J Trop Med Hyg 1999, 60:556-565.

16. Parker M: Re-assessing disability: the impact of schistosomal infection on daily activities among women in Gezira province, Sudan. Soc Sci Med 1992, 35:877-890.
17. Morgan OW, Brunette G, Kapella BK, McAuliffe I, Katongole-Mbidde E, Li W, Marano N, Okware S, Olsen SJ, Secor WE, Tappero JW, Wilkins PP, Montgomery SP: Schistosomiasis among recreational users of upper Nile River, Uganda. Emerg Inf Dis 2007, 16(5):866-868. doi:10.3201/eid1605.091740 http://wwwnc.cdc.gov/eid/article/16/5/09-1740_article.

18. World Health Organization: Accelerating work to overcome the global impact of neglected tropical diseases - a roadmap for implementation. Geneva, Switzerland: WHO/HTM/NTD/2012.1; 2012. http://www.who.int/ neglected_diseases/NTD_RoadMap_2012_Fullversion.pdf?ua=I\&ua=1.

19. Teesdale $\overline{C H}$, Chitsulo L: Schistosomiasis in Malawi-a review. Trop Med Parasitol 1985, 36(1):1-6.

20. Bowie C, Purcell B, Shaba B, Makaula P, Perez M: A national survey of the prevalence of schistosomiasis and soil transmitted helminths in Malawi. BMC Inf Dis 2004, 2004(4):49-57.

21. Mazigo DM, Nuwaha F, Kinung'hi SM, Morona D, de Moira AP, Wilson S, Heukelbach J, Dunne DW: Epidemiology and control of human schistosomiasis in Tanzania. Parasit Vectors 2012, 5:274.

22. Blair DM: Bilharziasis survey in British West and East Africa, Nyasaland and the Rhodesia. Bull WHO 1956, 15:203-273.

23. Pullanikkatil D, Mubako S, Phalira W, Chiotha S, Luhanga M: Schistosomiasis prevalence in Zomba, Southern Malawi. Afr Geogr Rev 2014, 33(1):36-51. doi:10.1080/19376812.2013.861758 http://dx.doi.org/10.1080/19376812. 2013.861758.

24. Jourdan PM: Schistosoma haematobium infection in the female genital mucosa: Immunohistochemical and clinicopathological analyses with respect to HIV target cells and vascularity in cervicovaginal tissue. Cross-sectional studies in Malawi and Madagascar. PhD Thesis. University of Oslo, 2013. [https://www.duo.uio.no/handle/10852/35961]

25. Logan S, Armstrong M, Moore E, Nebbia G, Jarvis J, Suvari M, Bligh J, Chiodini PL, Brown M, Doherty T: Acute schistosomiasis in travellers: 14 years' experience at the Hospital for Tropical Diseases. London Am J Trop Med Hyg 2013, 88(6):1032-1034. doi:10.4269/ajtmh.12-0646. Epub 2013 Mar 25.

26. Chipeta MG, Ngwira B, Kazembe LN: Analysis of Schistosomiasis haematobium infection, prevalence and intensity in Chikhwawa, Malawi: an application of a two part model. PLoS Negl Trop Dis 2013, 7(3):e2131. doi:10.1371/journal.pntd.0002131. Epub 2013 Mar 21.

27. Kjetland EF, Leutscher PDC, Ndhlovu PD: A review of female genital schistosomiasis. Trends Parasitol 2012, 28(2):58-65.

28. Blach O, Rai B, Oates K, Franklin G, Bramwell S: An outbreak of schistosomiasis in travellers returning from endemic areas: the importance of rigorous tracing in peer groups exposed to risk of infection. J Publ Health 2012, 34(1):32-36.

29. Kayuni S, Peeling R, Makaula P: Prevalence of S. haematobium infection among school children living in south-western shores of Lake Malawi. Masters of Science Thesis. London: School of Hygiene and Tropical Medicine; 2012.

30. Yildirmak MT, Funda S, Habip G, Arzu K: 2012. A Case of persistent urinary schistosomiasis transmitted through the Lake Malawi. Turkey Parazitol Derg 2012, 36:191-192.

31. Kapito-Tembo AP, Mwapasa V, Meshnick SR, Samanyika Y, Banda D, Bowie C, Radke S: Prevalence distribution and risk factors for infection among school children in Blantyre. Malawi PLoS Negl Trop Dis 2009, 3(1):e361. doi:10.1371/journal.pntd.0000361.

32. Save the Children: Controlling bilharzia in schools. Successes and lessons learned from Mangochi District, Malawi. Washington DC, USA: Save the Children; 2008. http://www.schoolsandhealth.org/_layouts/15/osssearchresults.aspx? $k=$ Controlling bilharzia in schools. Successes and lessons learned.

33. Yokota N, Kobayashi H, Tomita E, Kouchi Y, Kondo T, Hashimoto Y, Ito F, Tanabe K, Goya N, Toma H, Yamaura J, Kawamura S, Kobayashi M: A case of bilharziasis diagnosed 10 years later. Hinyokika Kiyo 2007, 53(5):319-322.

34. Van Delft F, Visser L, Polderman A, van Lieshout A: Cough and alterations in semen after a tropical swim. J Med 2007, 65(8):304-306.

35. Tsuboi T, Matsumoto K, Irie A, Hirayama T, Tsumura H, Hirai S, Satoh T, Iwamura M, Baba S, Takayama Y: A case report: Bilharzial schistosomiasis in the urinary bladder presented with gross hematuria. Hinyokika Kiyo 2006, 52(4):281-283.

36. Moore E, Doherty JF: Schistosomiasis among travellers returning from Malawi: a common occurrence - correspondence. Q J Medicine 2005, 98(1):69-71.

37. Tambo M, Fujimoto K, Inoue T, Tomioka A, Tanaka Y, Hirao Y, Yoshikawa M: Urinary schistosomiasis in a Japanese man. Int J Urol 2004, 11(7):563-566.

38. Kitayama S, Hyochi N, Kijima T, Iwai A, Takazawa R, Matsuoka Y, Otsuka Y, Yano M, Masuda H, Fujii Y, Kawakami S, Kobayashi T, Kihara K, Akao N: A case bilharziasis in a Japanese male. Hinyokika Kiyo 2004, 50(3):191-194. 
39. Nicolas X, Granier H, Laborde JP, Martin J, Klotz F: Family infected bathing in Malawi lake. Med Trop 1998, 58(4):414-415.

40. Silwal A, Sharma V, Qazi A, Subramaniam R: Schistosomiasis as a cause of terminal haematuria in a 14 year old boy in UK. Arch Dis Childhood 1997, 97(1):A20

41. Kjetland EF, Poggensee G, Helling-Giese G, Richter J, Sjaastad A, Chitsulo L, Kumwenda N, Gundersen SG, Krantz I, Feldmeier H: Female genital schistosomiasis due to Schistosoma haematobium. Clinical and parasitological findings in women in rural Malawi. Acta Trop 1996, 62(4):239-255.

42. Helling-Giese G, Sjaastad A, Poggensee G, Kjetland EF, Richter J, Chitsulo L, Kumwenda N, Racz P, Roald B, Gundersen SG, Krantz I, Feldmeier H: Female genital schistosomiasis (FGS): relationship between gynecological and histopathological findings. Acta Trop 1996, 62(4):257-267.

43. Poggensee G, Reimert CM, Nilsson LA, Jamaly S, Sjaastad A, Roald B, Kjetland EF, Helling-Giese G, Richter J, Chitsulo L, Kumwenda N, Gundersen SG, Krantz I, Feldmeier $\mathrm{H}$ : Diagnosis of female genital schistosomiasis by indirect disease markers: determination of eosinophil cationic protein, neopterin and IgA in vaginal fluid and swab eluates. Acta Trop 1996, 62(4):269-280.

44. Gundersen SG, Kjetland EF, Poggensee G, Helling-Giese G, Richter J, Chitsulo $L$, Kumwenda N, Krantz I, Feldmeier H: Urine reagent strips for diagnosis of schistosomiasis haematobium in women of fertile age. Acta Trop 1996, 62(4):281-287

45. Cetron MS, Chitsulo L, Sullivan JJ, Pilcher J, Wilson M, Noh J, Tsang VC, Hightower AW, Addiss DG: Schistosomiasis in Lake Malawi. Lancet 1996, 348:1274-1278.

46. Potasman II, Pick N, Abel A, Dan M: Schistosomiasis Acquired in Lake Malawi. J Travel Med 1996, 3(1):32-36.

47. News TDR: Malawi study signals need for more research on female genital schistosomiasis. TDR News 1996, 50:8.

48. Hunt L: Backpackers beware: bilharzia lurks in the lake. The Independent 1995. http://www.independent.co.uk/life-style/health-and-families/healthnews/backpackers-beware-bilharzia-lurks-in-the-lake-1596424.html.

49. Potasman I, Abel A: Schistosomiasis imported from Africa. Harefuah 1995 , 128(2):82-85.

50. Herwaldt BL, Tao LF, van Pelt W, Tsang VC, Bruce Jl: Persistence of Schistosoma haematobium infection despite multiple courses of therapy with praziquantel. Clin Infect Dis 1995, 20(2):309-315.

51. Loefler IJP: Schistosomiasis in Lake Malawi - Letter. 8 January, 1994. Brit Med J 1994, 308:138.

52. Eulderink F, Gryseels B, van Kampen WJ, de Regt J: Haematobium schistosomiasis presenting in the Netherlands as a skin disease. Am J Dermatopathol 1994, 16(4):434-438.

53. Pugh RNH: Schistosomiasis in Malawi - Letter to editor. 20 November 1993. Brit Med J 1993, 307:1354.

54. Whitworth JAG: Schistosomiasis may be contracted through swimming in Lake Malawi - Letter to editor. 9 October, 1993. Brit Med J 1993, 307(6909):936.

55. Wolfe M, Parenti D, Pollner J, Kobrine A, Schwartz A: Schistosomiasis in U.S. Peace Corps Volunteers - Malawi, 1992. Weekly Bull 1993, 42(29):565-570.

56. Russell JM, Macmichael C, Evans BA: Schistosomiasis. ...contrary to popular belief. Letter to editor. 9 October, 1993. Brit Med J 1993, 307(6909):937.

57. Madsen H, Stauffer JR Jr: The burrowing behaviour of Bulinus nyassanus, intermediate host of Schistosoma haematobium, in Lake Malawi. AfrJ Aquat Sci 2012, 37(1):113-116. doi:10.2989/16085914.2012.666383.

58. Madsen H, Bloch $P$, Makaula P, Phiri H, Furu P, Stauffer JR Jr: Schistosomiasis in Lake Malawi villages. EcoHealth J 2011, 8:163-176. doi:10.1007/s10393-011-0687-9.

59. Evers BN, Madsen H, Stauffer JR Jr: Crush-resistance of soft-sediment gastropods of Lake Malawi: implications for prey selection by Molluscivorous fishes. J Freshwater Ecol 2011, 26(1):85-90. doi:10.1080/ 02705060.2011.553921.

60. Kubiriza GK, Madsen H, Likongwe JS, Stauffer JR Jr, Kang'ombe J, Kapute F: Effect of temperature on growth, survival and reproduction of Bulinus nyassanus (Smith, 1877) (Mollusca: Gastropoda) from Lake Malawi. Afr Zool 2010, 45(2):315-320. http://dx.doi.org/10.3377/004.045.0210.

61. Stauffer JR Jr, Madsen H, Webster B, Black K, Rollinson D, Konings A: Schistosoma haematobium in Lake Malawi: susceptibility and molecular diversity of the snail hosts Bulinus globosus and B. nyassanus. J Helminthol 2008, 82(4):377-382. doi:10.1017/S0022149X08056290. Epub 2008 Aug 28.

62. Lundeba M, Likongwe JS, Madsen H, Stauffer JR Jr: Potential of Metriaclima lanisticola (Teleostei: Cichlidae) for biological control of schistosome intermediate host snails. Afr Zool 2007, 42(1):45-49. http://dx.doi.org/ 10.3377/1562-7020(2007)42[45:POMLTC]2.0.CO;2.
63. Jørgensen A, Gersdorff JLV, Kristensen TK, Madsen H, Russell SJ: Molecular phylogenetic investigations of Bulinus (Gastropoda: Planorbidae) in Lake Malawi with comments on the topological incongruence between DNA loci. Zool Scripta 2007, 36(6):577-585. doi:10.1111/j.1463-6409.2007.00298.x.

64. Lundeba M, Likongwe JS, Madsen H, Stauffer JR Jr: Preliminary study on the culture and breeding of Bulinus nyassanus (Mollusca: Pulmonata) under laboratory conditions. Afr Zool 2006, 41(1):143-144.

65. Evers BN, Madsen H, McKaye KR, Stauffer JR Jr: The schistosome intermediate host, Bulinus nyassanus, is a 'preferred' food for the cichlid fish, Trematocranus placodon, at Cape Maclear, Lake Malawi. Ann Trop Med Parasitol 2006, 100(1):75-85.

66. Madsen H, Stauffer JR Jr, Bloch P, Konings A, McKaye KR, Likongwe JS: Schistosomiasis transmission in Lake Malawi. Afr J Aquat Sci 2004, 29:117-119.

67. Brown DS, Hughes S, Kaukas A, Kumwenda N, Rollinson D, Sullivan JJ: Further record of Bulinus truncatus (Mollusca: Planorbidae) for Malawi, with evidence of compatibility with Schistosoma haematobium. J Afr Zool 1996, 110(5):333-339.

68. Chiotha S: Biological control of human schistosomiasis using snail eating fish. A Ph.D. Dissertation. USA: University of Maryland; 1990.

69. Van Bocxlaer B, Albrecht C, Stauffer JR Jr: Growing population and ecosystem increase human schistosomiasis around Lake Malawi. Trends Parasitol 2014, 30(5):217-220.

70. Stauffer JR, Madsen H, Rollinson D: Introgression in Lake Malawi: Increasing the threat of human urogenital schistosomiasis? EcoHealth $J$ 2013. doi:10.1007/s10393-013-0882-y.

71. Madsen H, Stauffer JR Jr: Schistosomiasis in Lake Malawi - Final project report. Schistosomiasis: ecological interactions among schistosomes, snail hosts, human hosts and fish predators; DBL- Center for Health Research and Development, Faculty of Life Sciences, University of Copenhagen, Copenhagen, Denmark and Pennsylvania State University, Pennsylvania, USA; 2008. http://ecosystems.psu.edu/research/reports/stauffer-malawi-08.

72. Stauffer JR Jr, Madsen H, Konings A, Bloch P, Ferreri CP, Likongwe J, McKaye K, Black KE: Taxonomy: A Precursor to Understanding Ecological Interactions among Schistosomes, Snail Hosts, and Snail-Eating Fishes. Trans Amer Fisheries Soc 2007, 136:1136-1145.

73. Stauffer JR Jr, Madsen H, McKaye K, Konings A, Bloch P, Ferreri CP, Likongwe J, Makaula P: Schistosomiasis in Lake Malawi: Relationship of fish and intermediate host density to prevalence of human infection. EcoHealth J 2006, 3:22-27. doi:10.1007/s10393-005-0007-3.

74. Madsen $\mathrm{H}$, Bloch P, Phiri H, Kristensen TK, Furu P: Bulinus nyassanus is an intermediate host for Schistosoma haematobium in Lake Malawi. Annals of Trop Med Parasitol 2001, 95(4):353-360.

75. Phiri K, Whitty CJM, Graham SM, Ssembatya-lule G: Urban/rural differences in prevalence and risk factors for intestinal helminth infection in southern Malawi. Annals Trop Med Parasitol 2000, 94(4):381-387.

76. Dacombe RJ, Crampin AC, Floyd S, Randall A, Ndhlovu R, Bickle Q, Fine PE: Time delays between patient and laboratory selectively affect accuracy of helminth diagnosis. Trans R Soc Trop Med Hyg 2007, 101(2):140-145.

77. Chitsulo L, Teesdale CH, Dixon H: Comparison of the Teesdale glass sandwich and Kato-Katz techniques for the diagnosis of Schistosoma mansoni: a double-blind study. Trop Med Parasitol 1990, 41(4):447-449.

78. Global Atlas of Helminth Infections (GAHI) 2001. [http://www.thiswormy world.org/maps/by-country/mw]

79. Berezowska S, Tomoka T, Kamiza S, Milner DA Jr, Langer R: Surgical pathology in sub-Saharan Africa-volunteering in Malawi. Virchows Arch 2012, 460(4):363-370. doi:10.1007/s00428-012-1217-z. Epub 2012 Mar 10.

80. Msyamboza K, Ngwira B, Banda R, Nkwanda S, Brabin B: Sentinel surveillance of Lymphatic filariasis, Schistosomiasis, Soil transmitted helminths and Malaria in rural southern Malawi. Malawi Med J 2010, 22(1):12-14.

81. Redman C, Spence G, Smith H, Smith K: Travel medicine: schistosomiasis in Scotland 2005-2009; laboratory confirmed 'imported infections', to week 53, 2009 \& 2008. HPS Weekly Rep 2010, 44:3.

82. Naus CW, Chipwete J, Visser LG, Zijlstra EE, van Lieshout L: The contribution made by Schistosoma infection to non-traumatic disorders of the spinal cord in Malawi. Ann Trop Med Parasitol 2003, 97(7):711-721.

83. Gordon MA, Zijlstra EE, Naus CWA, Visser LG, Molyneux ME, van Lieshout L: Schistosomiasis does not contribute to death or recurrence of nontyphoid Salmonella bacteremia in human immunodeficiency virus-infected Malawian adults. Clin Inf Dis 2003, 37:e177-e179. http://cid. oxfordjournals.org/content/37/12/e177.short. 
84. Kayuni SA: National survey to find out difficulties people face in taking regular antischistosomal drugs in Malawi. An MBBS dissertation. University of Malawi, College of Medicine: Blantyre, Malawi; 2003.

85. Bloch P, Makaula P: Survey report on schistosomiasis endemicity on Likoma and Chizumulu Islands. Malawi: Project Report; 2003.

86. Jackson F, Doherty JF, Behrens RH: Schistosomiasis prophylaxis in vivo using N, N-diethyl-m-toluamide (DEET). Trans R Soc Trop Med Hyg 2003, 97(4):449-450.

87. Randall AE, Perez MA, Floyd S, Black GF, Crampin AC, Ngwira B, Pistoni WN, Mulawa D, Sichali L, Mwaungulu L, Bickle Q, Fine PE: Patterns of helminth infection and relationship to BCG vaccination in Karonga District, northern Malawi. Trans R Soc Trop Med Hyg 2002, 96(1):29-33.

88. Trachtenberg JD, Jacobson M, Noh JC, Tsang VC, Ndoskoi J, Koster F: Schistosomiasis in expatriates in the Arusha region of Tanzania. J Travel Med 2002, 9(5):233-235.

89. Salanitri J, Stanley P, Hennessy O: Acute pulmonary schistosomiasis. Australas Radiol 2002, 46(4):435-437.

90. Waldman ADB, Day $J H$, Shaw P, Bryceson ADM: Sub acute pulmonary granulomatous schistosomiasis: high resolution CT appearances-another cause of the halo sign. Brit J Radiol 2001, 74:1052-1055.

91. Cooke GS, Lalvani A, Gleeson FV, Conlon CP: Acute Pulmonary Schistosomiasis in Travellers Returning from Lake Malawi, Sub-Saharan Africa. Clin Inf Dis 1999, 29:836-839.

92. Hall A, Nokes C, Wen ST, Adjei S, Kihamia C, Mwanri L, Bobrow E, de GraftJohnson J, Bundy D: Alternatives to bodyweight for estimating the dose of praziquantel needed to treat schistosomiasis. Trans $R$ Soc Trop Med Hyg 1999, 93(6):653-658.

93. MacLachlan M, Namangale JJ: Tropical illness profiles: the psychology of illness perception in Malawi. Pub Health 1997, 111(4):211-213.

94. Hipgrave DB, Leydon JA, Walker J, Biggs BA: Schistosomiasis in Australian travellers to Africa. Med J Aust 1997, 166(6):294-297.

95. Jelinek T, Nothdurft HD, Löscher T: Schistosomiasis in Travellers and Expatriates. J Travel Med 1996, 3(3):160-164.

96. Ager A, Cam S, MacLachlan M, Kaneka-Chilongo B: Perceptions of tropical health risks in Mponda, Malawi: Attributions of cause, suggested means of risk reduction and preferred treatment. Psychol Health 1996, 12(1):23-31.

97. Wiselka MJ, Nicholson KG: Schistosomiasis in Leicester. J Infect 1993, 26(2):177-179.

98. Ager A: Perception of risk for malaria and schistosomiasis in rural Malawi. Trop Med Parasitol 1992, 43(4):234-238.

99. Wolff T, Malewezi JG: Organization and decentralization of the Malawi National Bilharzia Control Programme. Trop Med Parasitol 1989, 40(2):201-204

100. Stauffer Jr. JR, Madsen H: Schistosomiasis in Lake Malawi and the potential use of indigenous fish for biological control. In Prof. Mohammad Bagher Rokni (Ed.), ISBN: 978-953-307-852-6. 2012. [http://www.intechopen.com/ books/schistosomiasis]

101. Phiri HTB: Distribution, density and infection rates of the intermediate hosts of Schistosoma species in selected lakeshore communities on Nankumba Peninsula. An MSc thesis. University of Malawi, Chancellor College: Zomba, Malawi; 2002.

102. Msukwa AV: The potential role of Lake Malawi National Park sanctuary areas for biological control of schistosomiasis and development of a sustainable fishery. A Master's thesis. RSA: Rhodes University; 1997.

103. Poole H, Terlouw DJ, Naunje A, Mzembe K, Stanton M, Betson M, Lalloo DG, Stothard JR: Schistosomiasis in pre-school-age children and their mothers in Chikhwawa district, Malawi with notes on characterization of schistosomes and snails. Parasit Vectors 2014, 7:153-164.

104. Madsen H, Stauffer JR Jr, Makaula P, Bloch P, Konings A, Likongwe JS: Bilharzia in Lake Malawi - What are the facts?. Malawi: Brochure; 2006.

105. Ministry of Foreign Affairs - Danida: Bilharzia Control Programme in Selected Lake Shore Communities of Lake Malawi. Copenhagen; Denmark: Project Completion Report Ref. No. 104.Malawi.1.MFS.4; 2000

106. Stauffer JR Jr, Arnegard ME, Cetron M, Sullivan JJ, Chitsulo LA, Turner GF, Chiotha S, McKaye KR: Controlling vectors and hosts of parasitic diseases using fishes. A case history of schistosomiasis in Lake Malawi. Bioscience 1997, 47:41-49.

107. Cetron M, Addiss DG, Colley D: Danger in Malawi - Letter to editor, 14 January. The New York Times: New York, USA; 1996. http://www.nytimes. com/1996/01/14/travel/l-danger-in-malawi-067334.html.

108. Wiselka MJ, Robinson MB, Clipsham K, Weddon S: The epidemiology of schistosomiasis in central Malawi. East Afr Med J 1988, 65(2):102-107.
109. Jourdan PM, Randrianasolo BS, Feldmeier H, Chitsulo L, Ravoniarimbinina P, Roald B, Kjetland EF: Pathologic mucosal blood vessels in active female genital schistosomiasis: new aspects of a neglected tropical disease. Int J Gynecol Pathol 2013, 32(1):137-140. doi:10.1097/PGP.0b013e31824fe327.

110. Special programme for research and training in Tropical Diseases: The social context of schistosomiasis and its control - an annotated bibliography. Geneva, Switzerland: World Health Organization (WHO); 2008.

111. Odiere MR, Rawago FA, Ombok M, Secor WE, Karanja DMS, Mwinzi PNM, Lammie PJ, Won K: High prevalence of schistosomiasis in Mbita and its adjacent islands of Lake Victoria. Western Kenya. Parasit Vectors 2012, 5:278.

112. Wilson ME: Environmental change and infectious diseases. Ecosyst Health 2000, 6(1):7-12.

113. Njenga SM, Mutungi FM, Wamae CN, Mwanje MT, Njiru KK, Bockarie MJ: Once a year school-based deworming with praziquantel and albendazole combination may not be adequate for control of urogenital schistosomiasis and hookworm infection in Matuga District, Kwale County Kenya. Parasit Vectors 2014, 7:74.

114. Sang HC, Muchiri G, Ombok M, Odiere MR, Mwinzi PNM: Schistosoma haematobium hotspots in south Nyanza, western Kenya: prevalence, distribution and co-endemicity with Schistosoma mansoni and soil transmitted helminths. Parasit Vectors 2014, 7:125.

115. Mwinzi PNM, Montgomery SP, Owaga CO, Mwanje M, Muok EM, Ayisi JG, Laserson KF, Muchiri EM, Secor WE, Karanja DMS: Integrated communitydirected intervention for schistosomiasis and soil transmitted helminths in Western Kenya - a pilot study. Parasit Vectors 2012, 5:182.

116. Remme JHF, Blas E, Chitsulo L, Desjeux PMP, Engers HD, Kanyok TP, Kengeya Kayondo JF, Kioy DW, Kumaraswami V, Lazdins JK, Nunn PP, Oduola A, Ridley RG, Toure YT, Zicker F, Morel CM: Strategic emphases for tropical diseases research: a TDR perspective. Trends Parasitol 2002, 18(10):421-426.

117. Meltzer E, Artom G, Marva E, Assous MV, Rahav G, Schwartz E: Schistosomiasis among travellers: new aspects of an old disease. Emerg Infect Dis 2006, 12(11):1696-1700. http://wwwnc.cdc.gov/eid/article/12/11/ 06-0340_article.

\section{doi:10.1186/s13071-014-0570-y}

Cite this article as: Makaula et al: Schistosomiasis in Malawi: a

systematic review. Parasites \& Vectors 2014 7:570.

\section{Submit your next manuscript to BioMed Central and take full advantage of:}

- Convenient online submission

- Thorough peer review

- No space constraints or color figure charges

- Immediate publication on acceptance

- Inclusion in PubMed, CAS, Scopus and Google Scholar

- Research which is freely available for redistribution

Submit your manuscript at www.biomedcentral.com/submit

C BioMed Central 